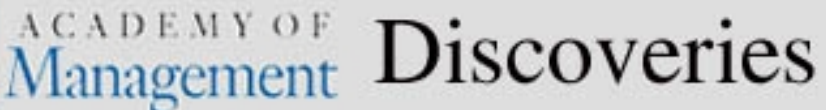

\section{No stone left unturned? Towards a framework for the impact of datafication technologies on organizational control}

\begin{tabular}{|c|l|}
\hline Journal: & Academy of Management Discoveries \\
\hline Manuscript ID & AMD-2019-0002.R3 \\
\hline Keyworcript Type: & Special Issue Digital Transformation \\
\hline Keys: & $\begin{array}{l}\text { Control Theory < Attitudes \& Motivation, Technology < Human Resource } \\
\text { Management \& Work Design, Qualitative Research Methods (General) } \\
\text { Research Methods }\end{array}$ \\
\hline $\begin{array}{l}\text { The goal of this paper is to develop an empirically-grounded framework } \\
\text { to analyze how new technologies, particularly those used in the realm of } \\
\text { datafication, alter or expand traditional organizational control } \\
\text { configurations. Datafication technologies for employee-related data- } \\
\text { gathering, analysis, interpretation and learning are increasingly applied } \\
\text { in the workplace. Yet there remains a lack of detailed insight regarding } \\
\text { the effects of these technologies on traditional control. To convey a } \\
\text { better understanding of such datafication technologies in employee } \\
\text { management and control, we employed a three-step, exploratory, multi- } \\
\text { method morphological analysis. In step 1, we developed a framework } \\
\text { based on twenty-six semi-structured interviews with technological } \\
\text { experts. In step 2, we refined and redefined the framework in four } \\
\text { workshops, conducted with scholars specializing in topics that emerged } \\
\text { in step 1. In step 3, we evaluated and validated the framework using } \\
\text { potential and actual users of datafication technology controls. As a } \\
\text { result, our refined and validated "Datafication Technology Control } \\
\text { Configurations" (DTCC) framework comprises eleven technology control } \\
\text { dimensions and thirty-six technology control elements, offering the first } \\
\text { insights into how datafication technologies can change our understanding } \\
\text { of traditional control configurations. }\end{array}$ \\
\hline
\end{tabular}

\section{SCHOLARONEm Manuscripts}


NO STONE LEFT UNTURNED? TOWARDS A FRAMEWORK FOR THE IMPACT OF DATAFICATION TECHNOLOGIES ON ORGANIZATIONAL CONTROL

\author{
SIMON SCHAFHEITLE * \\ (corresponding author) \\ simondaniel.schafheitle@unisg.ch \\ ANTOINETTE WEIBEL * \\ antoinette.weibel@unisg.ch \\ ISABEL EBERT ** \\ isabel.ebert@unisg.ch \\ GABRIEL KASPER * \\ gabriel.kasper@unisg.ch \\ CHRISTOPH SCHANK \\ christoph.schank@uni-vechta.de \\ ULRICH LEICHT-DEOBALD ** \\ ulrich.leicht-deobald@unisg.ch
}

* University of St. Gallen

Institute for Work and Employment Research, FAA-HSG

Müller-Friedberg Strasse 6/8 9000 St. Gallen Switzerland

\author{
** University of St. Gallen \\ Institute for Business Ethics, \\ IBE-HSG \\ Girtannenstrasse 8 \\ 9010 St. Gallen \\ Switzerland
}

$\$$ University of Vechta

Driverstraße 22 49377 Vechta Germany

The authors thank the anonymous reviewers for their valuable and constructive comments as well as for their helpful advice to improve the quality of the article. Our special thanks go to Claudio Kick, whose remarkable efforts in data collection have contributed to the overall success of the research project. Also, we are truly grateful for the excellent comments and critical thinking of Sim Sitkin and Chet Miller from which our paper benefited significantly. We are grateful for the dedicated efforts of Giulia Solinas and the entire editorial team of this special issue enabling such a fruitful exchange of ideas during the review and publication process. Finally, we thank our expert sounding board for the valuable insights as well as the Swiss National Science Foundation (NFP75) for the funding supporting this work. 


\title{
NO STONE LEFT UNTURNED? TOWARDS A FRAMEWORK FOR THE IMPACT OF DATAFICATION TECHNOLOGIES ON ORGANIZATIONAL CONTROL
}

\begin{abstract}
The goal of this paper is to develop an empirically-grounded framework to analyze how new technologies, particularly those used in the realm of datafication, alter or expand traditional organizational control configurations. Datafication technologies for employee-related datagathering, analysis, interpretation and learning are increasingly applied in the workplace. Yet there remains a lack of detailed insight regarding the effects of these technologies on traditional control. To convey a better understanding of such datafication technologies in employee management and control, we employed a three-step, exploratory, multi-method morphological analysis. In step 1, we developed a framework based on twenty-six semi-structured interviews with technological experts. In step 2, we refined and redefined the framework in four workshops, conducted with scholars specializing in topics that emerged in step 1. In step 3, we evaluated and validated the framework using potential and actual users of datafication technology controls. As a result, our refined and validated "Datafication Technology Control Configurations" (DTCC) framework comprises eleven technology control dimensions and thirty-six technology control elements, offering the first insights into how datafication technologies can change our understanding of traditional control configurations.
\end{abstract}

Keywords: Datafication, technology, organizational control configurations, artificial intelligence, multi-method morphological analysis 


\title{
NO STONE LEFT UNTURNED? TOWARDS A FRAMEWORK FOR THE IMPACT OF DATAFICATION TECHNOLOGIES ON ORGANIZATIONAL CONTROL
}

\begin{abstract}
INTRODUCTION
The powerful, accelerating effects of new technologies for digitized data-gathering and data interpretation, based on machine learning (ML) and/or artificial intelligence (AI), dominate the debate about the so-called digital transformation in the corporate world (Bamberger, 2018; von Krogh, 2018). Through this technological progress, a novel information phenomenon is emerging that creates finer levels of granularity and scalability of information (Gasser \& Almeida, 2017) and enables datafication, the process of transforming artifacts of social life into computerized, quantitative data to generate new forms of value (Cukier \& Mayer-Schoenberger, 2013). Thereby the logic of organizational value creation is fundamentally reconsidered and transformed into innovative processes (Lycett, 2013; Normann, 2001). This trend may significantly impact how firms organize work and jobs, which is underscored in the current debate on new ways of working by buzzwords such as "the second machine age" and the "fourth industrial revolution." Unlike other precursory technological advancements, such as the electronic-monitoring movement of the previous century (Grant \& Higgins, 1989; Stanton, 2000a), datafication technologies are not restricted to simple, easy-to-automate tasks; they also apply to "thinking work" (Phan, Wright, \& Lee, 2017). Datafication relies on ubiquitous computing which enables a pervasive connection of physical, social and technological spaces (Cascio \& Montealegre, 2016). As the term "information science" implies, datafication technologies not only observe and transform data but also offer an “information technology-driven sense-making process" (Lycett, 2013: 383). Thus, datafication may greatly expand and transform how we understand people management and, particularly, organizational control, which is defined as a process by which organizational leaders direct
\end{abstract}


attention and motivate employees to act in desired ways to achieve the organization's objectives (Cardinal, 2001; Cardinal, Sitkin, \& Long, 2010; Kirsch, Ko, \& Haney, 2010).

In business practice, datafication technologies have begun to change the nature of organizational control. For instance, some practice-oriented articles have posited that "Big employer is watching you" (Solon, 2017) or "Why a robot could be the best boss you ever had" (Chamorro-Premuzic, 2016). Companies, for example, have started to experimented with performance-development apps or deep learning for employee performance scoring matrices (e.g., Wright, 2015) to align employee interests to those of the organization. Datafication can contribute to this alignment in two ways. First, datafication rests on ubiquitous and low-cost data collection technologies, such as smart ID badges, wearable GPS devices or bio-radio-frequency ID (bio-RFID) chips, which all allow for increased employee tracking and the translation of analog data into a digitized form. Additionally, contextual and unstructured data is collected by sensors in "smart things." This is driven forward by so-called "Internet-of-things" advancements, such as chairs noting unergonomic postures and the times at which workers are most productive (Wang \& MacLellan, 2018) or "smart" toilets that can track health and drug-related issues (Petre, 2018), by which these technologies conceptualize and codify social actions. Second, datafication is driven by data interpretation technologies, which are based on algorithmic decision-making, machine learning or AI to identify patterns, trends and relationships in data. These technologies allow a more fine-grained description of digitized social action and, in some cases, a prediction, or even a prescription, of employee behavior (Konrad, 2013; Zax, 2013). For instance, the communication tool "Slack" is supposed to facilitate better workplace cooperation, by enabling employees to observe when and how organizational members generate work-related knowledge (Woyke, 2018). The AI-augmented software "Starmind" aims to make expert knowledge more accessible within an organization by allocating scores to individual users (Sandle, 2018). In this, an algorithm ranks between higher- and lower-performing 
knowledge experts to promote a "gamification" feeling, giving awards to motivate employees to share their knowledge freely. As these examples demonstrate, data-driven technologies can support organizational control by their monitoring, evaluating and even incentivizing potential; however, these novel developments have only been rarely reported on by scholars in the organizational control literature and have yet to be systematically discussed. We lack a profound understanding of the phenomenon of datafication and the evolving "control" technologies. In particular, there is no coherent categorization of such datafication technology controls. Cardinal, Kreutzer, and Miller (2017: 560) stressed that control research has not kept pace with the stark changes in technology, and highlighted the need for further research in this area; it is especially unclear how datafication technologies influence traditional control elements and configurations (Cardinal et al., 2017: 583). For example, traditional organizational control typically takes the form of a supervisor setting goals for employees, monitoring the process of achieving those goals and evaluating employee performance. So far, such traditional control is typically depicted without a reliance on technologies. Hence, we need a framework that enables organizations to identify, evaluate and even create novel technological opportunities for organizational control. From a more theoretical perspective, we need to analyze whether and how these datafication technologies expand and/or transform traditional organizational control elements, and which novel control configurations could emerge. This is because "no one can predict with certainty all of the ubiquitous-computing innovations that the coming years will bring, and realizing their full potential will not be easy" (Cascio \& Montealegre, 2016: 354).

Given the nascent and limited understanding of how datafication technologies expand or transform organizational controls, we have developed a datafication technology control framework with an iterative research design to grasp the complexities of datafication. More specifically, we have developed this framework in the form of a morphological analysis, based on three steps: (1) 
interviews with technological experts; (2) topic-driven workshops with researchers; and (3) validation workshops with managerial users. We chose a morphological analysis because this is most suitable for describing an evolving space of datafication control elements. This is important for describing a phenomenon in its early and emerging stages. Morphological analysis can capture the nonlinearity, asymmetry and equifinality of a configurational, holistic, system-oriented approach towards organizational control. Based on earlier findings on how technology alters management techniques, we propose that technological progress will expand established modes of organizational control more linearly, and/or will lead to datafication technology control configurations (DTCCs) composed of datafication control elements and/or previous ones (Cardinal et al., 2017). Our framework suggests that this datafication-driven change in organizational control might be more transformative than hitherto accounted for in management and organization science.

\section{CONFIGURATIONAL CONTROL THEORY AS A DEFAULT POSITION}

In this paper, we focus on organizational control, defined as the process by which organizational members direct the attention of employees and motivate them to act in desired ways to achieve the organization's objectives (Cardinal, 2001; Cardinal et al., 2010; Kirsch et al., 2010). In addition, we employ a configurational perspective on control (Dess, Newport, \& Rasheed, 1993; Short, Payne, \& Ketchen Jr, 2008). Such a perspective argues for a balanced interplay of various control elements jointly impacting the outcome variables of interest (Cardinal et al., 2017; Misangyi et al., 2017). Accordingly: (1) control needs to be captured in a multifaceted way to correspond to the multitude of possible control elements; and (2) any control configuration setup has to allow for different approaches to balance the control elements because control effectiveness can be determined in various ways. In the following, we outline the basic premises of organizational 
control, discuss the most prominent framework of control dimensions and elements, and explain how the configurational view of organizational control captures control configurations as multidimensional constellations of various control dimensions and elements.

\section{Basic Premises of Organizational Control}

Organizational control is defined as an influence process that seeks to align employees with the organization's objectives (Cardinal, 2001; Cardinal et al., 2010; Kirsch et al., 2010). In line with Flamholtz, Das, and Tsui (1985), organizational control is embedded in the wider context of an organizational structure and strategy. While organizational control is goal-oriented, the definition of strategic goals is viewed as a context factor, and thus not part of the organizational control function. We capture organizational control as a way of implementing these strategic goals (Sitkin, Cardinal, \& Bijlsma-Frankema, 2010). Also, while organizational control coordinates individual efforts towards organizational goals, it is still firmly executed in existing organizational structures, defining the controllers and the controlled. In most of the literature, managers are viewed as controllers and employees as those being controlled (Long \& Sitkin, 2018).

Research on organizational control spans a century. Starting with early insights from Weber (1922) and Fayol (1949), it reached peak interest in the late 1970s to 1990s, with the important works of Ouchi (1980; Ouchi \& Maguire, 1975) and Eisenhardt (1985). It is beyond the scope of this paper to provide a comprehensive review of the rich body of literature on organizational control. In line with the research focus of this paper, we have based our subsequent review on the control system architecture of organizations from a general management perspective (Cardinal, 2001; Cardinal et al., 2017; Cardinal et al., 2010; Cardinal, Sitkin, Long, \& Miller, 2018; Kirsch et al., 2010).

\section{Control System Architecture: Control Elements, Dimensions and Systems}


The analytical components used to study a control system architecture are control elements categorized into control dimensions. Cardinal and co-authors (2010) offer a parsimonious overview, and distinguish organizational control along two dimensions: (1) control formality; and (2) control targets. These two dimensions can be further divided into control elements. Firstly, control can be either formal or informal (Cardinal, Sitkin, \& Long, 2004). Formal control refers to codified written rules, and is usually enacted by supervisors setting team or employee-oriented objectives or standards (Vlaar, Van den Bosch, \& Volberda, 2007), supervising the degree of compliance through monitoring by the provision of regular feedback (Flamholtz et al., 1985; Weibel, 2007) and enacting appraisal or sanctioning practices (Cardinal et al., 2010; Jaworski, 1988). In contrast, informal control is less/not formalized, and is enacted via the enforcement of norms, values and shared (cultural) beliefs. Informal control typically consists of the sense-making of day-to-day behavior (Cardinal et al., 2018), as well as protecting, but also refining, applicable organizational norms (Barker, 1993). Following the typology proposed by Cardinal and colleagues (2010), we argue that formal and informal control are distinct, and conceptually independent, concepts. Secondly, the dimension "control target" comprises three elements. Control can be targeted towards inputs; that is, focusing on how employees are chosen, qualified or allocated to tasks. Control can also be targeted towards behaviors and processes; that is, safeguarding the "rules of the game", ensuring that actors behave in a certain way. Finally, control can be aimed at outputs, where certain predefined (performance) standards have to be reached (Cardinal et al., 2004, 2010; Snell, 1992). Similarly to the elements of the control formality dimension, these targets of control are distinct and independent.

Organizational control scholarship offers a longstanding body of work on how these control elements and dimensions are understood to interact in broader control systems. Three perspectives stand out, offering a distinct view on the interaction of such elements/dimensions with regard to 
control effectiveness - the singular, weak and strong holistic approaches to organizational control (Cardinal et al., 2017). The singular approach focuses on single organizational control dimensions, and emphasizes how one control element in the same dimension can contribute to organizational effectiveness, more or less in isolation. For instance, Tannenbaum (1962) discusses the dimension "amount of control" arguing that participatory control is better able to meet employees' needs than more autocratic control. The weak holistic approach studies various control dimensions and elements at the same time, with one specific control system being the preferred one for the situation (Cardinal et al., 2017). It thus follows a contingency perspective, where the most effective control system is dependent on specific environmental characteristics (e.g., Eisenhardt, 1985; Ouchi, 1979). For instance, Ouchi (1979: 843) finds clan control systems, composed of more informal control elements (reciprocity norms, socialization tactics), to be superior in their effectiveness in a dynamic and unpredictable environment. Finally, the strong holistic approach emphasizes how various, and equivalent, control dimensions/elements interact and blend to shape control effectiveness (Cardinal et al., 2004, 2010; Cardinal et al., 2018; Simons, 1994). In contrast to the weak holistic approach, which considers one type of control to be superior, the strong holistic approach argues that multiple dimension/element constellations can be effective. In the following, we explore this approach in greater depth.

\section{Strong Holistic Approach to Organizational Control and Configurational Theory}

The strong holistic approach to organizational control belongs to the wider family of configurational theories (Dess et al., 1993; Miller, 1987; Short et al., 2008). Rooted in organizational design research (Bedford \& Malmi, 2015; Ménard, 2009), configurational theory 
assumes that a variety of internally-consistent design patterns emerge to align organizations to their external environment. The associations between the constituent dimensions and elements of such patterns and the context are nonlinear, asymmetric and/or equifinal with regard to their marginal contribution to a system's effectiveness (Bedford \& Malmi, 2015: 6; Meyer, Tsui, \& Hinings, 1993; Miller, 1987; Misangyi et al., 2017). For instance, Cardinal and colleagues (2004) study the evolution of control in growing organizations in this holistic sense. The authors explore how temporary imbalances in an organizational growth process create dynamic adaption patterns, which are then resolved by organizational actors creating novel, better-fitting control configurations.

The strong holistic approach of organizational control reflects the configurational perspective particularly in respect to three assumptions. Firstly, control systems are best depicted as multidimensional constellations of various control elements (Misangyi et al., 2017) that need to be balanced to be effective in the context of any outcome variable of interest (Cardinal et al., 2017). Secondly, control elements are not enacted separately in organizations, but as an aligned set of interdependent attributes (Miller, 1987; Misangyi et al., 2017). Thirdly, the emerging control configurations can occur in a nonlinear, asymmetric and equifinal way. Nonlinearity manifests in a way that makes certain combinations of control elements synergistic, whereas others might be "toxic combinations" (see Kepes \& Delery, 2007). Equifinality means that different combinations of control elements might lead to the same result. Finally, for some configurations, the absence of certain control elements (or their inverse relations) might be important, and consequently configurational theory allows for asymmetry. Thus, a strong holistic approach towards organizational control configurations appears to be well suited to capturing the manifold design options enabled by datafication technologies for organizational control. This approach enables the analysis of effective organizational control as a complex composite, enacted and modified by 
organizational actors in the context of an ambiguous and fluid environment, which is a characteristic of contemporary organizations (Cardinal et al., 2017: 571; Dougherty, 2016).

\section{RESEARCH DESIGN AND PROCESS}

\section{Research Design}

Our goal is to develop an empirically-grounded framework to analyze how datafication technologies expand or alter effective organizational control configurations. To this end, we find an exploratory approach warranted. Empirically, there have been relatively few attempts, so far, to capture organizational control in a strong holistic sense (see Bedford \& Malmi, 2015; Cardinal et al., 2018; Sandelin, 2008), none of which have been targeted at including datafication controls. This allows us to identify, collect, categorize and specify the dimensions and elements pertinent to datafication technology controls, in order to suggest how existing and future DTCCs can be composed.

Also, our research design has to account for three distinct phenomenological properties of datafication controls. Firstly, the empirical phenomenon is complex and multidimensional, exhibiting properties that are typically hard to quantify. This calls for an exploratory research design based on data triangulation from multiple sources and perspectives. Secondly, the empirical phenomenon is changing quickly. New datafication technologies with additional features are constantly emerging, and many additional usages are "discovered" by controllers only after the technologies have been explored in companies. Consequently, to describe possible control elements and barely-emerged configurations, we need a method that would allow for the mapping of future options or for "inventive engineering" (Arciszewski, 2018). Thirdly, the "datafication technology market" is characterized by a large number of rapidly-growing, heterogenous market participants. Various, and often rival, perspectives concerning the empirical phenomenon exist. 
An iterative research design can capture such heterogeneous perceptions through back-and-forth refinements with existing organizational control elements and knowledge about traditional organizational controls.

Hence, a morphological analysis is well suited to meet these characteristics, as a nonlinear method for describing complex and multidimensional phenomena, fraught with uncertainty about evolving, real-world configurations (Ritchey, 2002, 2011, 2012). Zwicky (1969) developed such a method to investigate the complete set of property combinations for the then-unknown jet and rocket propulsion systems, and to delineate future development opportunities (Ritchey, 2002). More recently, morphological analyses have been applied to similar complex, emerging and nonlinear phenomena in the field of management, for business-model invention and description (Seidenstricker, Rauch, \& Dallasega, 2017; Seidenstricker, Scheuerle, \& Linder, 2014), mapping managerial behavioral strategies in evaluation and decision-making (e.g., Wilding, Sharif, \& Irani, 2006) or developing a co-creation framework (Frow, Nenonen, Payne, \& Storbacka, 2015). The goal of a morphological analysis is to construct a morphological box with a parsimonious, twodimensional space. This box allows the mapping of all relevant elements. The dimensions and the specifying elements make up the morphological field, which in our case can describe and analyze the combinatory logic of DTCCs in the workplace. Therefore, existing and future DTCCs can be shown, discussed, and explored further in future research, including asymmetric or equifinal configurations.

Morphological analyses follow the principle of rule-guided iteration (Ritchey, 2011; Turley, Richardson, \& Hansen, 1975). Specific data collection and analysis methods, however, are not prescribed. Methods applied in morphological analyses in the field of management range from more deductive approaches, based on literature reviews, to more inductive ones, developed via iterative discourses among scholars and/or practice experts (Im \& Cho, 2013; Seidenstricker et al., 
2014). In our case, we used the iterative logic of morphological analysis, as we: (1) triangulated the empirical data with theoretical insights from the literature; and (2) refined the morphological box in distinct research steps, to incorporate various perspectives (see Linstone \& Turoff, 2002). The resulting morphological box was constructed and refined in a rule-guided and transparent manner, allowing for its replication, adjustment and extension (Bacharach, 1989; Frow et al., 2015). In the following, we refer to the morphological box resulting from our morphological analysis as a "framework" for DTCCs.

\section{Research Process}

Our research process comprises three steps, as presented in Figure 1.

Insert Figure 1 about here

The aim of step 1 was to explore and gather data on datafication technology control dimensions and elements. We based our insights on semi-structured interviews with technological experts. These interviews followed the rules of a problem-centered interview (Witzel \& Reiter, 2012), starting from the premise that the interviewer is well-informed, but adapts and grows his/her knowledge through talking with insiders (Witzel \& Reiter, 2012: 2). Qualitative content analysis was used to extract the findings from the interview material via a combination of concept-driven and data-driven code development (Mayring, 2015). The aim of step 2 was to refine and, if needed, redefine our framework (control dimensions and control elements) in multiple rounds of workshops with various scholars, in order to satisfy the scientific criteria of consistency, validity and parsimony (Meyer, 2007; Ritchey, 2012). Each workshop was centered on specific questions that emerged from step 1 or were related to scientific quality criteria. The aim of step 3 was to evaluate our framework for plausibility and relevance. We organized two workshops, discussed it 
with human resources (HR) practitioners, and had them apply a configurational logic to it. Figure 2 gives a substantial overview of how the application of an iterative logic helped us to arrive at specific datafication control dimensions and elements, starting from initially broad themes. It further illustrates how we generated and condensed the insights over the three research steps, indicates what questions were raised at which time points, and shows how we pursued this logic until no open questions/broad themes remained, leaving only concrete datafication control dimensions and elements.

Insert Figure 2 about here

\section{DATA-GATHERING AND ANALYSIS}

\section{Step 1: Identifying Control Design Options of Datafication Technologies with Experts}

Participants. We followed a theoretical sampling strategy to structure our expert interviews (Eisenhardt \& Graebner, 2007: 27). We interviewed technological experts, technology developers, technology suppliers and sophisticated users to acquire a more specific understanding of the design and implementation options of datafication technology controls. These experts were working in companies that can be described as revelatory cases (see also Yin, 2013); that is, they were working for the "big players" in the field of information and communications technology development, application or consulting, and in vanguard companies in datafication technology implementation. In terms of selecting experts inside these companies, we strongly adhered to the criterion of an expert's competence and knowledge about the issue being studied, as proposed by Kumar and colleagues (2016: 1634). In addition, we ensured sufficient professional and hierarchical variability in our overall expert selection (see Table 1 for an overview of our interview partners). 
Data collection. We conducted twenty-six semi-structured, problem-centered interviews, on site and over six months in 2017. The interviews were carried out in German and English, and were audio-recorded (duration 30-60 minutes) and subsequently transcribed. Each interview covered three topics. We: (1) discussed how the experts understood people management and organizational control in the context of datafication; (2) talked about what tools or applications they develop, use or sell, what the inherent technologies are able to do, and what the potential future customization of these technological applications might look like; and (3) asked them how their products compared to those of their competitors or, for sophisticated users, asked them to share their past/present user experiences.

Data analysis and results. The interviews were coded via concept- and data-driven code development (Mayring, 2015). An initial coding frame, using deductively-formed codes from the control literature, was substantially amended by subsequent inductive coding to challenge and broaden the original frame (see Kuckartz \& Rädiker, 2019). We ensured intercoder reliability by using a codebook and training procedures, as well as by continuously discussing ambiguous codes within a transdisciplinary group of six researchers (Kurasaki, 2000). Furthermore, we triangulated our insights using articles from practitioner journals and the public media on the changing effects of technology on people management, and organizational control enactment in organizations. A range of control elements emerged from our expert interviews. Table 2 provides a detailed summary of the emergent design options (see also the boxes with bulb icons in Figure 2, step 1).

Insert Table 2 about here

In addition, the experts mentioned two further, non-technical themes as important drivers behind how technology is adopted in companies, for organizational control in particular. We categorized 
them as: (1) normative concerns, relating to business ethics and legal issues; and (2) employee perceptions, seen as hindering, or sometimes enabling, effective datafication technology implementation (see dotted circles in Figure 2). For instance, one interviewee from a large, multinational technology consulting firm noted that his company aimed to "highlight ethical concerns to ... clients as applicable [and,] at the same time[,] the client decides the shape of the product. There are conflicting interests in ethics within companies. The workers' council needs transparency. At the same time, a recruiter can record data that no one else will potentially ever know about." A technology consultant from another multinational company noted about the second topic: "Keep in mind, if you collect employee data, you collect everything, but the data should not be used for everything. ... If[,] nowadays, a company works with a[n analytics] tool, it needs to invest in a supportive corporate culture, in checks and balances[,] as well as in appreciation for the employees. The implementation of such a tool must be balanced with 'soft things'; it needs trust on both sides." Several additional remarks on normative concerns and employee perceptions not only highlighted their importance, but also provoked us into designing workshops in step 2 with scholarly experts, in order to explore these themes thoroughly.

\section{Step 2: Redefining and Refining the Framework for Datafication Technology Control Configurations}

Participants. We invited scholarly experts to four workshops to cover additional perspectives, deepen the themes from step 1 , and challenge the consistency, validity and parsimony of the quality criteria for the newly-developed framework. See Table 3 for an overview.

Insert Table 3 about here 
The first workshop provided a clearer understanding of the normative and regulatory questions relating to datafication technology controls, and there was discussion on how these insights could be displayed in the framework. The questions posited were debated with scholars from the areas of business ethics, macroeconomics, strategic management and employment/data-protection law. The second workshop focused on the relationship between organizational control and employee perceptions, such as trust, motivation and acceptance, which were discussed by experts from the fields of trust theory, employee motivation, HR practices and performance monitoring. The third workshop emphasized the construction of the framework, helped by experts in research methods relating to framework building (i.e., typologies, taxonomies, morphological analysis methods). We asked them to scrutinize how the emerging framework fulfilled the criteria of consistency and parsimony. Finally, a fourth workshop focused on the framework's validity with regard to configurational control theory, from the perspectives of two renowned scholars in the field (Cardinal et al., 2010).

Data collection. We gathered all the data in the same manner. After presenting the evolving framework in a deliberately engaging manner, so as to signal our openness to new perspectives, we allowed the participants to discuss it, raise questions and/or add further insights on possible novel design options (see Gläser \& Laudel, 2009). For each workshop, we made a memory protocol, taking photos of flipcharts or similar documents produced during the discussion. After each workshop, two of the authors discussed what was learned, and adjusted the framework accordingly. Subsequently, the framework was discussed again with at least one expert from the workshop, either via phone or e-mail, to check its plausibility.

Data analysis and results. In line with the seven-step approach of Spiggle (1994), the workshop insights were (a) categorized, (b) abstracted, (c) compared, (d) dimensionalized, (e) 
integrated, (f) refuted and (g) iterated (see also Frow et al., 2015: 469). Figure 2 illustrates this procedure, with gear icons highlighting the ways in which former control dimensions or elements were altered; the bulb icons indicate novel insights. During the entire process, but particularly in workshops 3 and 4 , the quality criteria for the categorizations were salient. Consistency was assessed by examining whether combinations of control dimensions and elements could coexist and made sense from logical, empirical and practical standpoints (Ritchey, 2011: 14). We accounted for validity (Meyer, 2007: 28) by assessing the rigor of the framework using configurational control theory and eradicating ambiguity in the definitions and categorization criteria. Finally, parsimony/simplicity relates to the fact that our framework had to include the fewest, most relevant dimensions in a comprehensible and easy-to-apply manner.

Additional datafication technology control dimensions and elements emerged during each workshop. As a result of workshop 1, we relabeled several dimensions and elements, as the scholars pointed out that any control configuration has to adapt a system's property perspective. Ethical and legal considerations resulted in three new dimensions. First, the possibility for employees to opt out was perceived to be important across disciplines. Second, the question of data visibility and comparison was raised by the legal scholars. "Volume of Data" emerged as a third dimension. As a result of workshop 2, we additionally reviewed the literature on electronic performance monitoring, as the workshop participants argued it held insights into the effects of monitoring practices on employee attitudes, although being narrow in scope (see Table 4). Also, some of the behavior-oriented researchers drew analogies to enabling and coercive control (Alder \& Borys, 1996) and the findings from HR practice research (e.g., Sapegina \& Weibel, 2017). As a result, some control elements were added (such as "Function Creep" and "Non-job-related Behavior Control") and further control dimensions emerged ("Control Scope," "Openness for Employee Participation," "Target of Control”). 
Insert Table 4 about here

Workshop 3 was held to ensure the consistency of the framework and to discursively revisit the marginal utility and relevance (parsimony) of each dimension and element. As a consequence, we changed the dimension "Data Sources" from the two elements "Digital Sources" and "Digital and Physical Sources" to "Structured Data Sources" and "Unstructured Data Sources." In addition, the dimension "Volume of Data" was eliminated (indicated by a cross in Figure 2), as this characteristic of datafication technology control would become visible merely by mapping the various control configurations in our framework. Workshop 4 led to a critical revisiting of our framework, resulting in the additional dimension "Target of Control" and the additional control element "Opt-in Options Possible."

\section{Step 3: Evaluating and Validating the Datafication Technology Control Configuration Framework}

Participants. Twelve HR practitioners were invited to the first workshop, selected based on their ability to judge the framework from a user perspective. Workshop 2 was hosted jointly with a vanguard technology company, not included in step 1, and was attended by eight practitioners. All HR practitioners held senior management positions that included both HR/people management analytics and/or HR performance management processes.

Data collection. We gathered data in the same manner for both workshops. The plausibility of our framework was evaluated in two ways. We first introduced some representative use cases found in the press as a conversation starter, reading and discussing the implications of these choices of management. Then, we asked the practitioners to apply a configurational logic to the framework; that is, they had to draw "lines" through the framework prototype to describe the DTCCs outlined 
in those representative cases. Second, we asked them to think about use cases that best reflected their organizational reality. We repeated the procedure to inquire whether the configurations in the framework represented their organizational reality well, whether the configurations made sense from an application perspective, or if any logical or empirical inconsistencies remained. Disagreements, conceptual ambiguities and vagueness of the assignments were resolved discursively in the plenary session. Similarly to step 2, we made a memory protocol and took photos of the drawn configurations.

Data analysis and results. The scripts used in the workshops, and the full set of questions used for the discursive validation, are depicted in Table 5. The framework was perceived as a practical and genuine representation of the attendees' organizational reality. The HR practitioners, however, proposed minor adjustments to the wording, and simplified one of the dimensions by splitting it into two (“Reference Group” was separated from “Data Visibility”).

Insert Table 5 about here

\section{RESULTS}

In the following, we present the resultant DTCC framework, with its final set of dimensions and specifying elements. To illustrate how the framework can contribute to the analysis of real-world phenomena, we apply two exemplary-use cases to the finalized version.

\section{Framework on Datafication Technology Control Configurations}

As a result of our morphological analysis, the framework is represented as a morphological box composed of eleven DTCC design dimensions and thirty-six datafication technology control 
elements that further specify the dimensions. Each dimension contains two to six elements (thirtysix in total; see Figure 3). Morphological analysis is built on distinct, rather than continuous, categories. For instance, the dimension "Control Timing" can be specified by two distinct elements - before or after signing the employment contract. They are different in the sense that they are distinguishable from each other by their unique role in technology-assisted organizational control; however, the morphological approach also facilitates the concurrent existence of multiple elements. For example, an organizational control system composed of distinct singular control practices can comprise a set of different dimension/element combinations at the same time. Thus, for instance, an organization could monitor employees before and after they sign a contract with the company.

Overall, one possible configuration of one element per dimension represents one DTCC tool (i.e., one morphotype). All possible element configurations result in multiple morphotypes (i.e., configurations). These morphotypes can be interpreted as design features for describing and conceptualizing a system of DTCC inside an organization. This configurational logic, with a special emphasis on the overall DTCC system, resonates with scholarly advancements on strong holistic control systems (Cardinal et al., 2017) from both a theoretical and empirical perspective. In the following, we sketch the conceptual body and defining categories for each dimension.

Insert Figure 3 about here

(1) Control timing. The first defining feature of our DTCC framework is whether organizational control is executed (a) before or (b) after employees have signed an employment contract. Before-contract control can be summarized as all procedures applied to (actively) source, screen and select participants in a directed, and also undirected, manner. After-contract controls 
are procedures that seek to align employee and organizational goals. The traditional organizational control literature has not clearly distinguished control timing, albeit the input control has always been separated from the behavior/process and output control (e.g., Eisenhardt, 1985). However, input control has often been used as an umbrella term for several control practices, such as selection, training and socialization, with very different timing dimensions (Snell, 1992), which in itself has seldom been analyzed in depth. To further differentiate control, timing could be useful because it potentially impacts privacy and its perception. For instance, data collected in the selection process could cover more intimate and personal moments than data collected in the workplace, particularly if social media is scanned. Privacy issues, however (and according to the electronic monitoring literature), could strongly influence employee acceptance of DTCCs (Grant \& Higgins, 1989, 1991). Moreover, our experts highlighted that technologies for targeting job candidates before the employment relationship begins are increasingly in demand. Active sourcing, matching organizational profiles with (externally-purchased) individual profiles, in combination with the use of scanning applications, automated letter analysis and hiring robots, are accelerating in practice.

(2) Target of control. This dimension addresses the question of control targets. Here, we follow the traditional distinction of the organizational control literature between (a) input, (b) process/behavior and (c) output/performance. Additionally, our analysis revealed (d) norms as a target of datafication technology control. Input control seeks to measure employees' abilities, skills and attitudes, matching them to companies, jobs, teams or project demands. Note, however, that input control, defined in this way, can be timed before or after an employee has signed a contract. Input control can be technically assisted by automatic mood/sentiment analyses or by competencemanagement/active-sourcing software. Process/behavior control seeks to align employee 
behaviors with prescribed procedures and behavioral patterns, enabled by software and tracking devices that match defined processes with employee behavior (e.g., fraud analytics, compliance software apps, geo-localization tracking, camera surveillance, facial recognition). Output/performance control seeks to match employee outputs with performance targets, and is technologically enabled by feedback apps, people-management dashboards and technologies that track goal accomplishment to promote learning and motivation.

Finally, datafication technologies enable the control of norms in the workplace in order to align employee values with corporate values, and to create strong norms of company-preferred behavior (e.g., sentiment analyses that highlight client advisors' feelings and attitudes in consulting situations, which can be matched to predefined standards of smile authenticity). Soon, automated learning and AI solutions will play an even greater role in controlling norms by enabling value alignment via some form of mind control or by mimicking peer pressure. For example, some devices have already been developed that are loosely termed "brain-hacks," which direct the brain in some - at present, clumsy - sense (see Meckel, 2018).

(3) Control scope. Traditional configurational control theory distinguishes between formal and informal control, and views both as constitutive of an organizational control system (Cardinal et al., 2017); however, our experts argued that the distinction between formal and informal control is partly artificial and arbitrary, regarding datafication technologies, because all technologyassisted types of controls are formally coded, and hence would fall into the realm of formal control. This distinction still needs to be accounted for, however. We argue that the use of datafication technologies allows for the monitoring and evaluation of employee behaviors and attitudes beyond the traditional reach of supervisors (i.e., areas formerly limited to the realm of informal control). 
Hence, we suggest that the reach of control into areas that are hard to quantify, and those formerly considered private, is another important dimension of our DTCC.

"Control Scope" can be divided into three categories based on whether employee-related information is generated: (1) on the premises and in relation to task performance; (2) on the premises and in relation to contextual performance; or (3) off the premises. Task-performancerelated data on the premises is enabled by a myriad of technologies, most of which have been discussed in the electronic performance-management literature (Aiello \& Kolb, 1995; DeTienne, 1993). Contextual-performance-related data - that is, data quantifying the extra-role behaviors of employees - can be based on AI-team-designed applications, in which emphasis is put on cooperative team climates, engagement or caring behaviors (e.g., Google's OXYGEN program). Furthermore, several datafication technologies capture off-the-premises employee data; for instance, via matching the competency model requirements with leisure time content from Facebook posts or WhatsApp messages.

(4) Data sources. Our analysis reveals that DTCCs can be based on either (a) structured data sources that relate to data to which the meaning of information is already attached via predefined "write-in" spaces, or (b) unstructured data sources in which no predefined meaning is attached. For instance, Starmind is a technology solution based on AI-supported algorithms that claim to be able to identify organizational experts on any subject matter, and connect them with the employees who need access to previously-undocumented company knowledge. This knowledge is built on structured and mainly unstructured data sources. In this example, the tapping of unstructured data is enabled by IBM WATSON pattern-recognition software, in which company e-mail is checked for word stems, indicating not only the content of problem-solving activities, but also depicting networks such as "who asks whom for what at which time point." 
(5) Openness for employee participation. The framework displays whether DTCCs allow employees to participate in the control process by design. The relevance of this design feature for employee acceptance is emphasized both in the electronic performance-monitoring literature (Alder, 2001), and also by the distinction of enabling and coercive controls (Adler \& Borys, 1996). Our experts suggested differentiating between highly-participatory and little to non-participatory elements in the design of organizational control practices. For instance, cloud-based open-data applications, such as instant feedback applications, allow employees a greater variety of participation. Here, employees can evaluate predetermined content, and express their opinions via open-ended-question formats, possibly contributing additional data input. At the same time, possibilities for employee participation might be reduced when employees are limited in their scope of choice for feedback content.

(6) Possibility for employees to opt out. Another important dimension is whether there is (a) a possibility to voluntarily opt in to the system, (b) a possibility to opt-out from an otherwise default system, or (c) no choice but to accept it. This distinction is strongly influenced by discussions with our technical experts (in step 1) and practitioners (in step 3), who all pointed towards differing legal backgrounds. Some countries are stricter in protecting employee data, demanding that companies actively ask employees whether they are willing to participate (scenario a). Examples include getting employees' consent to RFID implants to allow them to access copy machines and coffee facilities, or their voluntary use of "smartwatches" in corporate health programs. Here, the voluntary opt-in option is chosen - it is neither expected that all employees participate, nor is it forced upon them. Other legal frameworks operate on the principle that opting in is the default situation, although employees have the possibility to opt out (scenario b). Examples include mobile phone applications that enable knowledge-sharing behavior via the geo- 
tracking of employees, with the choice of disabling the tracking function or the smartphone itself. Finally, some industry regulations (e.g., those of banks) require the systematic monitoring of employees' data to prevent liability claims, often not allowing for opting out until the employment relationship has been terminated (scenario c).

(7) Transparency. Our results suggest that DTCCs may convey different degrees of "Transparency" on how precisely employees are informed about what is and what is not controlled. Generally, a DTCC system may (a) disclose all information on how the system operates and which control features are used in which places, or (b) not disclose any information on its modus operandi. The insights from the expert interviews point to a third category, however - (c) the functionality of technologically-assisted control systems can evolve, often quickly, and thus produces what has also been termed "function creep," - in the sense that novel control opportunities emerge, but are not communicated to employees (Ball, 2010). For instance, some companies support a healthy employee lifestyle by introducing the voluntary use of Fitbits, particularly in private security and military contexts. If an employee wears one of these all day, it can measure all kinds of physical activity, including moments of intimacy and/or geographical location, which might not be job-related. Some organizations might be tempted to use this data for purposes other than those explicitly outlined.

(8) Granularity to which inference is possible. DTCCs also differ regarding the granularity to which inference is possible. Our experts highlighted the importance of this dimension, since datafication technologies enable managers to make a range of inferences at various levels. Technically, the analysis of the data is targeted towards the following three possible inference levels: (1) employee level; (2) team/division level only; or (3) company level only. For instance, engagement surveys are anonymous when paper-based, but if they are conducted online, 
managers might be able to obtain the IP address or geolocation and identify the employee. Data being available in a much more granular and complex format allows for more individual-targeted insights. Thus, in theory, organizations could obtain deep insights into areas of an employee's life, as well as their psychological disposition. The negative effects of such potential pervasiveness have been highlighted by the electronic performance-monitoring literature, which has demonstrated that performance monitoring perceived as less pervasive has higher employee acceptance than one perceived as quite intrusive (e.g., Bain \& Taylor, 2000; Stone \& Kotch, 1989). In practice, certain safeguards can stop managers from doing this. Such safeguards often stem from legal frameworks, or are inspired by ethical considerations in line with a corporation's values and norms. Still, it is important to distinguish the level of granularity to which data is collected.

(9) Analytical capacity. This capacity mirrors a decisive feature for distinguishing DTCCs from traditional organizational control. Datafication technologies not only monitor employees, but also evaluate and model the collected data, even to the degree that the technology suggests novel organizational goals based on the data analysis. Three categories of "Analytical Capacity" can be distinguished - descriptive, predictive and prescriptive. Descriptive analysis offers a description of the status quo. It ties information together for more fact-based decision-making; for instance, in the form of performance scores and key performance indicators. Predictive analysis enables the forecasting of future employee behavior and performance, based on the likelihood of an outcome occurring if relevant predictors are considered. This type of analysis is often depicted as an earlywarning system. Finally, prescriptive analysis proposes scenario-based estimations of the probability of an outcome, and recommends different courses of action. Prescriptive analytics techniques differ from predictive ones by their learning capacity; that is, they can improve, providing more precise estimations and evaluations each time they are applied (Davenport, 2013; Krumeich, Werth, \& Loos, 2016). Controls, which rely on prescriptive analysis, can automate the 
goal-setting process, to a certain extent, and may impact the definition of organizational goals. For instance, some US and Japanese companies are said to employ "robots as bosses" where algorithms independently set and adjust goals, with a manager only being consulted when legal or ethical issues arise (Hitachi, 2015; Hongo, 2015).

(10) Reference group. This describes the reference point(s) collected data is compared to and inference is based on. Relying on insights from our expert interviews, we propose splitting this dimension of the comparison of employees into the following categories: (1) with oneself over time; (2) with peers in the team; (3) with peers in other teams; (4) with all employees in the organization; and (5) with standardized employees, in the sense of organizational and industry standards/benchmarks. In particular, this mirrors the discussion on the effect of competition. A comparison of employees with themselves, over time or against abstract industry benchmarks, is likely to be learning-related and to induce playful, gaming-oriented competition. On the other hand, a comparison with peers inside the team or across the whole organization, or between teams, might evoke quite different, and potentially more harmful, competition (Sapegina \& Weibel, 2017: 718).

(11) Data visibility. This refers to the question of who can access and evaluate the collected data. Some technical experts saw this as an important differentiation option for their products, some insisted that the collected data should only be available to employees, and others suggested that it could be shared company-wide. The electronic performance-monitoring literature has also argued that data access is important for ascertaining employee reactions to monitoring (Aiello \& Kolb, 1995). Here, we distinguish six dimensions: (1) analyzed employees; (2) the line manager; (3) the HR department; (4) expert committees; (5) open-data company access; and (6) open-data third-party access. These categories mirror the central notion of Bernstein's (2017) argument on 
transparency versus privacy. He shows that different levels of data visibility are linked to different levels of control effectiveness (2017: 244). Hence, differentiation is important for subsequent testing of the effects of different degrees of data visibility on the effectiveness of DTCCs.

\section{Datafication Technology Control Configurations: Two Exemplary Cases}

Control configurations are made visible by selecting default options for a datafication technology tool, hence by "drawing lines" through the framework. Similarly to the validation workshops in research step 3, we use two cases that are well documented in the literature to help us understand DTCCs in an exemplary fashion. Figure 4 illustrates the application of the framework via a graphic visualization, with ORION at United Parcel Service (UPS; solid line) and Starmind at Company Alpha (dotted line) appearing as DTCCs.

Insert Figure 4 about here

(1) ORION at UPS. Since 2010, UPS has developed and implemented an intelligent navigation technology called ORION (On-Road Integrated Optimization and Navigation), which is applied as a datafication tool for organizational control. ORION is based on a combination of sensors, GPS tracking and intelligent data processing, which aims to optimize the routing of parcel delivery vehicles (Konrad, 2013). It has been touted as saving 8.5 million gallons of fuel and reducing $\mathrm{CO}_{2}$ emissions by 85,000 metric tons annually, as well as streamlining package delivery options in general (see Holland, Levis, Nuggehalli, Santilli, \& Winters, 2017: 12). ORION is said to be linked to the performance management of individual employees (Bruder, 2015). UPS is aiming to optimize employees' stops per on-road hour, a key measurement ready to be linked with some of the sensors used for ORION, but critics suggest that handling packages at UPS feels like living in a panopticon (Bruder, 2015; Zax, 2013). 
We can now delineate how the use of ORION configures one aspect of UPS's organizational control. The control takes place after the contract has been signed. It is targeted at employee outputs, but it can easily be used to monitor employee behaviors. For instance, critics claim that “too many toilet breaks" would lead to an employee's negative evaluation by their employer (Bruder, 2015; Zax, 2013). As this example highlights, the control scope reaches beyond task behavior/performance, and the data is unstructured. Employee participation is low, but the system is pitched to make better routing decisions than those made by drivers, and thus participation would undermine this target. There are no clear opt-out possibilities when an employee drives a UPS delivery truck (Holland et al., 2017; Zax, 2013). It is difficult to judge the system's transparency or whether the employee has the opportunity to consent. It appears that some options are still being developed, and thus a function creep on what is done with the data seems possible. The granularity of inference is on the individual employee level. The system is based on prescriptive analytics, as optimized routes are suggested to the drivers as a preferred option; for example, dependent on the likelihood of traffic jams (Holland et al., 2017). We have no information on the reference group chosen for some of the system features. It seems possible that stops per on-road hour are used for rankings, so the reference group would be other drivers. Indeed, one article has suggested that line managers not only have access to the data (next to the routing optimizers and HR), but also "post printouts of driver data every day" (Bruder, 2015).

(2) Starmind at Company Alpha. ${ }^{1}$ Alpha, a large Swiss company, has been implementing Starmind's AI software for knowledge management purposes. This software is connected to employees' computers and the company's intranet. It analyzes, verbatim, in-house e-mails in real-

\footnotetext{
${ }^{1}$ This example was originally brought up in a workshop, and is also based on our confidential case-study research (not part of this study).
} 
time and tracks information on who asks whom, why and how often. The software development company argues that Starmind is very efficient in managing distributed employee knowledge, assisting companies in bridging organizational silos and enabling organizational learning in general (Starmind, 2019a). In addition, answers are validated and scored by an AI algorithm (Starmind, 2019a). Starmind's self-learning software also generates scores for each user, dependent on how often a user communicates with other people or how "well" an employee performs in answering the questions posed to them. Furthermore, this score might also be used to incentivize knowledge-sharing (Starmind, 2019b) and, relatedly, trigger fuzzy-tasking behavior (Roberts, 2010).

Based on how Alpha uses Starmind, the following configuration can be depicted. Control activities take place after the formal beginning of the employment contract, targeting processes/behaviors (i.e., who asks whom?) as well as outputs. As the software analyzes in-house e-mail content and tracks information on who asks whom, why and how often, Starmind's scope comprises task performance and contextual performance. The data is unstructured as e-mail traffic, and questions and answers are analyzed and saved as they are processed by employees. The system allows for high employee participation regarding how to use the system; however, all employees have to participate because there are no clear opt-out functions available. The system's transparency is limited, as the employees do not seem to understand how their score is computed. The granularity of inference is high because scores are calculated for each employee individually. The system is mainly based on descriptive analytics of social capital and knowledge-sharing behavior, but also allows for predictive analytics. For instance, Starmind identifies who should interact more with whom and who has the highest probability of solving a particular problem. There are at least two reference groups for comparing data - all other employees in the company and industry standards. 
Finally, Starmind rating scores are visible to HR managers as well as expert committees, whereas "being an expert" tags are visible to all company members.

\section{DISCUSSION}

The goal of this paper was to explore and map how datafication technologies expand, transform or even disrupt traditional organizational control regimes. To do this, we developed a framework based on a morphological analysis. The research steps were designed to cater to both empirical rigor and practical relevance. The resulting framework opens a broad array of possibilities of how control practices can be combined, balanced, changed and enacted to adjust to the specific needs of organizations. In the following, we highlight "what is new, if anything?" when it comes to DTCCs. We then delineate novel questions inspired by our research, and seek to define a future research agenda on datafication technology control. Finally, we discuss what particular challenges datafication technology controls generate for practical application.

\section{What is New with Datafication Technology Control Configurations, if Anything?}

Our first aim was to describe the novel phenomenon of datafication and its impact on organizational control in a coherent and structured way. We employed a morphological analysis to create a unified picture of an emerging phenomenon. A phenomenon, which, at present, is contested, with each of our experts interviewed, the literature reviewed and the scholars scrutinized coming up with a different picture of what DTCCs look like. Thus, our framework is, to our knowledge, the first that seeks to systematically integrate insights from datafication technology controls across research and practice-knowledge domains in a systematic, phenomenon-driven fashion. To this end, we had to further develop the rule-guided iteration doctrine (which is only vaguely defined by morphological analysts) in a way that reflects our field of interest, which is 
characterized by rapidly-emerging datafication technology options, deep and long-standing knowledge from a variety of disciplinary fields, and a lack of communication among these different perspectives. During our expert interviews, the interviewees were very clear and knowledgeable when discussing their insights about the phenomenon; however, glaring blind spots remained when it came to reflecting upon key aspects outside their work portfolios. The researchdesign-driven, stepwise development of the DTCC framework (i.e., the morphological box), by building and enlarging our knowledge base, has served the purpose of moving us beyond the "limited selection of control mechanisms" (Cardinal et al., 2018: 581) discussed in the field of control research ${ }^{2}$ and, at the same time, has integrated various disciplines and bases of knowledge concerning datafication technologies.

Our framework integrates these diverse perspectives, which can best be illustrated using examples. For instance, we captured how the dimension "transparency", (i.e., employees' knowledge of the control system) changed during our morphological analysis. The technical experts regarded such knowledge as a design-based feature of the system in a binary "present/not present" fashion. So did the scholars from the field of organizational control and those with a more micro-level perspective. Contrary to this, however, the monitoring/surveillance literature treated transparency as emerging and fluid (e.g., McNall \& Roch, 2009; Zweig \& Webster, 2002). Similarly, the development of a technology that allows expanding functionalities that are often not foreseeable from the outset can only be captured by a further design option - "function creep", that now constitutes an important element of our DTCCs framework.

\footnotetext{
${ }^{2}$ For a better understanding, please refer to Figure 2 to see how our insights developed across domains of knowledge, as indicated by the bulb, gear and cross icons.
} 
Another key element - namely, whether employees can opt-out from the system - emerged from normative concerns raised by the technology experts. In addition, the legal experts consulted later made it clear that datafication control technologies need to explicitly provide for an opt-out dimension because this is required by the major regulatory frameworks, such as the European General Data Protection Regulation (REGULATION (EU) 2016/679; Bhave, Teo, \& Dalal, 2020). Also, the more micro-oriented scholars built on these requirements, suggesting that an opt-in possibility might be an even better implementation for making sure that employees voluntarily give their consent.

Our second aim was to answer how datafication technologies change the emphasis, expand and transform traditional organizational control elements (see Bernstein, 2017). We found that datafication technologies clearly change the emphasis of what elements of organizational control have to be analyzed more thoroughly. More specifically, Cardinal and co-authors (2017: 578) stressed that input control has been relatively neglected in previous research. This stands in stark contrast to what the interviewed technology suppliers considered to be a growing and strong market, since they explained that "technologies that target the control of job candidates before their employment [have] witnessed an increasing demand." Also, the ability of datafication controls to analyze unstructured data outside the workplace, and to form predictions about future behaviors based on this data, clearly shows that we need to focus on the element of formal input control more strongly in our future research (e.g., Cascio \& Montealegre, 2016).

Another key finding was that datafication technologies expand organizational control. Additional and emerging control characteristics need to be balanced in order to establish a context-sensitive, effective control in the light of technological innovation. For instance, legal frameworks differ, and opt-out functions and degrees of data granularity need to be adapted accordingly (Weber, 
2013). Furthermore, design features of datafication control systems, such as the degree of participation, control timing and the transparency of controls, might become more important for some effectiveness-outcome criteria of organizational control (e.g., Bain \& Taylor, 2000; Stanton, 2000a). In addition, the limits of organizational control might have to be readjusted. Many experts highlighted the increased ability to monitor what employees do, but technology will enable sensemaking and action delineation from data patterns that previously needed to be interpreted by human beings. One expert highlighted how the combination of "virtual" traces and "real life", physical traces expands the reach of control: "In the past, one could only make a digital comparison of collaboration. Nowadays, you can combine that with a physical component." Yet none of the experts seemed to believe that limitless control is currently possible and/or desirable. Bearing in mind the increasing criticism of "surveillance capitalism" (Zuboff, 2019) mapping the new limits will be an important future task for control scholars.

With ongoing innovation, emerging technologies also have the potential to transform or even to disrupt organizational control. We suggest two areas likely for this to happen: First, technology might make informal control obsolete. Datafication technologies permit to monitor almost everything from behaviors to attitudes, norm obeyance and emotions, and these control insights can be shared. In turn, the generated data can form the basis of organizational learning, defining of goals and standards, and the disciplining of employees. This leaves little room or necessity for informal control. Some technological advancements may even change human habits and norms, ranging from simple nudging to stimulate desired behavior (Ariely, 2017) to measuring alterations in the human brain (Meckel, 2018). Hence, norm alignment, a former core feature of informal control, might be carried out in a completely different manner. Second, the technologies studied can describe situations, draw inferences and prescribe novel ways of action, as well as generating new goals. Consequently, even the definition of the organizational goals might become part of the 
organizational control system. Control results might be automatically translated into organizational goals without human oversight. As a result, datafication technology control might alter the tasks of organizational leaders. Perhaps leadership could become equally subject to automation. This sparks important questions in the field of employment law (Prassl, 2018, 2019), but also calls for further research in the field of leadership. Hence, from the perspective of organizational control, both these developments - the diminishing importance of informal control as well as the automation of leadership functions - raise the question of whether we should better reconceptualize organizational control as control in organizations. It is becoming increasingly opaque who is controlling whom through the sophisticated use of technologies.

\section{Future Theorizing and Future Research}

We suggest that our framework lends itself to the future theorizing of control theory and empirical research drawing on qualitative comparative analysis (QCA; Ragin, 2008). As a first step, to generate testable propositions, future research must theorize more specifically how and why DTTCs are linked to which particular outcomes. In this section, we demonstrate how testable models could be delineated from the framework, using one possible outcome criterion as an example. Namely, we will discuss how DTCCs are linked to positive employee perceptions. With this effectiveness criterion in mind, we first show how the tenets of holistic control theory can be further developed. We then examine more "futuristic" areas of research, inspired by our framework, as well as adaptation patterns of datafication technology controls. Finally, we briefly introduce what an empirical investigation of effective DTCCs could look like.

Delineating configurations. Strong holistic control theory “investigates how combinations of control mechanisms affect organizational processes and effectiveness" (Cardinal et al., 2010: 131). Thus, the interplay between different dimensions and complementarities of combinations are 
of dedicated interest. On one hand, our framework could be systematically used to predict "deadly combinations" concerning positive employee perceptions. The literature on electronic performance-monitoring can serve as a springboard, as it has examined how particular design features contribute to employees' negative perceptions of electronic control. Potentially, low levels of employee participation and extensive monitoring of non-job-related behaviors could create deadly combinations with other control dimensions/elements that affect employee perceptions negatively (Spitzmüller \& Stanton, 2006); for instance, arguing that low employee participation exerts a negative influence, independently of how well other design features of the control configuration are chosen.

On the other hand, future studies could juxtapose certain configurations (see the comparison between ORION and Starmind) to study the complementarities of specific control systems. Datafication technology control "archetypes" could be constructed, for instance, by differentiating novel coercive technology control systems from enabling ones (see Cardinal et al., 2017: 583). In general, research has shown that control systems are perceived to be enabling if employees feel that such systems assist them in their daily work, leave leeway to adapt when needed and enhance learning opportunities, while allowing some form of self-determination (Alder \& Borys, 1996; Sitkin, Sutcliffe, \& Schroeder, 1994; Weibel \& Six, 2013). In contrast, coercive control systems are taken as a signal of distrust, being perceived as rigid and impractical, and seemingly prioritizing compliance over learning (Alder \& Borys, 1996; Costa \& Bijlsma-Frankema, 2007; DeHart-Davis, 2008). Hence, enabling control systems should correlate positively with perceptions of utility, user acceptance and employee trust in the organization (or in the controller). We propose that such positive perceptions are closely linked to a coherent interplay of the whole configuration of a datafication control model. The ORION case could be viewed as a typical coercive configuration of datafication technology control. Its "low participation" combined with "function creep" and 
"data visibility for HR and supervisors" might have a complementary effect on employee perceptions of coerciveness. Employees might initially be told that the system is used for reducing the company's carbon footprint. If they subsequently discover that it is used for strict monitoring and evaluation purposes, this could result in a negative spiral of low trust or distrust.

Dynamics of datafication technology controls. The effective balancing of control elements is likely to change over time, irrespective of the chosen outcome variable. We believe that one particular self-reinforcing driver is salient - an illusion of control through tracking technology (Neff \& Nafus, 2016). There is a strong narrative of a strong belief in technology, which would rid us of human bias and allow us to control aspects that humans are unable to control due to a lack of expertise (Finlay, 2014; Leicht-Deobald et al., 2019; Strauss, Kristandl, \& Quinn, 2015). Selftracking technologies promise the possibility of tracking and categorizing each essential aspect of human action and social interaction (Neff \& Nafus, 2016). This illusion of control is likely fueled by the black box character of data-processing in models and systems driven by ML and/or AI - a black box that is difficult to comprehend ex-post, even for technology developers (DeBrusk, 2018; Pasquale, 2015). This "tech-solutionism" will presumably impact the use and enactment of datafication technology control in comparison with more traditional forms of control. This belief might lead to the misleading impression that gaps previously common in organizational control will be closed through more granular and omnipresent tracking; however, the gaps commonly acknowledged in control have not been closed, as there is no possibility for their accurate numeric measurement. This situation is particularly true for social actions. As a result, the growing use of datafication in organizational control might fail to deliver the desired outcomes.

Adaptation patterns. Our framework serves as a suitable point of departure for addressing the lack of empirical research into adaptability outcomes, as indicated in the systematic review by Cardinal and colleagues (2017). The core question to be addressed is: What factors influence 
adaptation patterns in DTCCs? We propose that the use and sophistication of DTCCs are strongly influenced by organizational (both monetary and technological) and HR resources. Yet given the already very lively discussions taking place in practice journals, we also believe that ethical considerations, legal frameworks and organizational stakeholders will massively influence how DTCCs are enacted. While technological solutions to assist organizational control are rapidly becoming less costly (Bassi, 2011), significant investments remain, making it likely that large organizations might not use the full potential of DTCCs. Problems in using DTCCs can stem from a technical angle; for instance, alignment with the pre-existing infrastructure and platforms. At the same time, a lack of interest in investing in DTCCs can also derive from a shortage of staff expertise in information, data and business analysis (Angrave, Charlwood, Kirkpatrick, Lawrence, \& Stuart, 2016). Most strikingly, HR or organizational development departments, well placed to custom tailor DTCC systems, often neither have enough technical expertise nor a high technological affinity (Fleming \& Artis, 2010). Furthermore, implementing datafication technology controls is not only a resource and competence issue, but could be greatly hampered by ethical and/or legal concerns (Hendrickx, 2018). Worker councils, labor unions, civil society organizations and privacy scholars have highlighted potentially adverse effects on privacy by increased monitoring in the workplace (boyd \& Crawford, 2012; Crawford \& Schultz, 2014). At the same time, investors are starting to pay attention to ethical concerns in the digital realm because major data scandals have affected the financial performance of several companies.

Testing effective DTCCs. Future research could use our framework to analyze effective datafication technology configurations via fuzzy-set QCA (fsQCA, see Misangyi et al., 2017; Ragin, 2008). For instance, researchers could employ our framework as a data-gathering method, asking technical or HR experts from NASDAQ 100 firms to map their current use of DTCCs in their organizations. This could then be matched with effectiveness criteria, such as investment 
attractiveness. For instance, financial analysts could be approached to rate a company's capacity for product innovation or financial performance. In such a case, a four-value fsQCA could be applied to determine necessary and sufficient datafication technology control elements, with regard to investment attractiveness.

Additionally, an agenda for further research might entail more in-depth qualitative research endeavors for theory building. For instance, multiple case-study research, with a longitudinal research design, could contribute to a nuanced understanding of how DTCCs relate to salient employee-level attitudes, such as learning, trust or motivation (e.g., Spitzmüller \& Stanton, 2006; Zweig \& Webster, 2002), in order to be effectively implemented. In a hypothetical scenario, multiple case-study research could follow the logic of theoretical replication (Eisenhardt, 1989; Yin, 2018). Initial propositions are derived from deviant cases - so-called "prediction outliers" (Zott \& Huy, 2007) - and then validated using insights from extreme cases (i.e., "model-fit outliers") in order to increase their validity and plausibility through constant challenge and adjustment "extreme" and revelatory insights. Finally, theoretical replication involves the selection of one or two typical cases for literal replication (Yin, 2018) to promote the external validity of the emerging theoretical model.

In a similar vein, future research could contribute to DTCC theory by building from a large-Nbased ML perspective (Choudhury, Allen, \& Endres, 2018) in order to investigate groups of businesses applying the same DTCCs and their related outcomes, as well as to establish the importance of each configurational element or dimension. If researchers could access large-scale organizational control data to study the emerging patterns from an organizational control system using datafication technologies, regression analysis could help to establish possible effect sizes and directions, or researchers could work with random-forest analysis and decision trees. Ideally, researchers could explore novel and robust patterns in such datasets, allowing them to engage in 
inductive or abductive theory building, based on ML's identification of novel patterns in organizational control data. ML methods might be more effective than traditional large-N methods in illuminating interactions and nonlinear effects.

\section{Limitations and Practical Implications}

Inevitably, our research is not without limitations, but these can be used to guide future research. The DTCC framework emerged from an exploratory research endeavor and, to the best of our knowledge, it was the first study to perform morphological analysis in the field of organizational control. As outlined in our methodology, morphological analyses are well suited to "digging deep" into complex and emerging empirical phenomena, in order to present a multifaceted representation for their description and analysis; however, and due to its empirical context of depicting phenomena in emergence, morphological analysis is not best suited to obtaining the most parsimonious solution. As such, we encourage further applications of our framework to real-world DTCC architectures, so as to increase the parsimony and strengthen the external validity of our framework.

Furthermore, our framework has important implications for practitioners, as it may serve as a powerful management tool. Managers might use our framework to comprehensively map the current state of the art on tech-based control in their organization. In doing so, managers could identify and investigate numerous combinations of DTCCs. Our open framework sensitizes processes of high dynamics to change, and also promotes unexpected interactions between different control-element configurations. In addition, it might help to structure an organization's DTCCs. The framework could increase managers' awareness of their DTCC architecture. Managers would be able to evaluate whether their current DTCC architecture complies with the 
company's strategy and its HR philosophy, and be able to delineate an HR roadmap for designing customized DTCC systems.

Finally, our framework challenges the role of management in a novel way. As outlined above, datafication technologies transform organizational control, such that they reduce the domain for informal control. Hence, and in line with the evidence-based recommendations of Tomczak, Lanzo, and Aguinis (2018), it may well be that managers will have to give up their established self-perception of guiding employees' behaviors toward organizational goals or rethink their strategies of how to achieve such an outcome. We believe that our framework can transform leadership tasks in at least three ways. First, managers would have to be more context-sensitive in the effective balancing of DTCC dimensions. Echoing the work of Cardinal (2001), for a particular combination of DTCC dimensions to increase desirable work outcomes, such as employee satisfaction, the employees' trust in the employer or the increased goal alignment will be heavily dependent on the context (see Searle et al., 2011). Hence, managers' ability to "walk the DTCC tightrope" will be crucial in determining whether a DTCC system turns out effectively; that is, perceived as either enabling or coercive. Second, our results call for an increase in managers' care and empathy because employees' compliance with the system will be a critical success factor. It will be up to the manager to anticipate, communicate and evaluate the appropriate degree of permeation into employees' (private) lives, even if business needs alternative behaviors to be adopted. Third, our results indicate that managers will have to develop a basic skillset to enable them to understand the technical properties of the DTCC system. To put it in a nutshell, datafication is going to change established modes of organizational control in the workplace. Our framework is a first step to provide for guided managerial thinking to embrace datafication in organizational control in a strategic manner for the wellbeing of businesses and their employees. 
TABLE 1

\section{Overview of Experts and Types of Companies Participating in the Research}

\begin{tabular}{|c|c|c|c|c|c|}
\hline ID & $\begin{array}{l}\text { Professional Designation / } \\
\text { Job Title }\end{array}$ & $\begin{array}{l}\text { Industry / } \\
\text { Sector }\end{array}$ & $\begin{array}{l}\text { End-user or } \\
\text { Developer } \\
\text { Company }\end{array}$ & $\begin{array}{l}\text { Company Financial } \\
\text { Performance in bn } \\
\text { US\$ in } 2017\end{array}$ & $\begin{array}{l}\text { Scope of Business } \\
\text { Activity (Interviewee } \\
\text { Affiliation) }\end{array}$ \\
\hline I1 & $\begin{array}{l}\text { Advanced Data Analyst \& } \\
\text { AI Specialist }\end{array}$ & Hardware/Software & $\begin{array}{l}\text { End-User \& } \\
\text { Developer }\end{array}$ & 90 (rеvепие) & $\begin{array}{l}\text { Multinational group } \\
\text { with a national } \\
\text { subsidiary in } \\
\text { Switzerland }\end{array}$ \\
\hline $\mathrm{I} 2$ & $\begin{array}{l}\text { Professor of Applied \& } \\
\text { Future-oriented } \\
\text { Technologies }\end{array}$ & University & Developer & $\begin{array}{l}0.097 \\
\text { (financial volume) }\end{array}$ & Swiss company \\
\hline $\mathrm{I} 3$ & Country Consultant HR & Telecommunications & $\begin{array}{l}\text { End-user \& } \\
\text { Developer }\end{array}$ & 48 (GAAP results) & \multirow{2}{*}{$\begin{array}{l}\text { Multinational group } \\
\text { with a national } \\
\text { subsidiary in } \\
\text { Switzerland }\end{array}$} \\
\hline I4 & Collaboration Engineer & Telecommunications & $\begin{array}{l}\text { End-user \& } \\
\text { Developer }\end{array}$ & 48 (GAAP results) & \\
\hline I5 & $\begin{array}{l}\text { Head of HR Services } \\
\text { Delivery \& Business } \\
\text { Management }\end{array}$ & $\begin{array}{l}\text { Banking and } \\
\text { Insurance }\end{array}$ & End-user & 0.331 (net income) & \multirow[t]{2}{*}{ Swiss company } \\
\hline I6 & $\begin{array}{l}\text { Head of HR Reporting \& } \\
\text { Analytics }\end{array}$ & $\begin{array}{l}\text { Banking and } \\
\text { Insurance }\end{array}$ & End-user & 0.331 (net income) & \\
\hline
\end{tabular}




\begin{tabular}{|c|c|c|c|c|c|}
\hline $\mathrm{I} 7$ & Founder \& CEO & $\begin{array}{l}\text { Management } \\
\text { Consulting }\end{array}$ & Developer & 0 (start-up) & \\
\hline I8 & Presales Senior Specialist & $\begin{array}{l}\text { Software } \\
\text { Development }\end{array}$ & $\begin{array}{l}\text { End-user \& } \\
\text { Developer }\end{array}$ & 27.5 (total revenue) & \multirow{2}{*}{$\begin{array}{l}\text { Multinational group } \\
\text { with a national } \\
\text { subsidiary in } \\
\text { Switzerland }\end{array}$} \\
\hline I9 & $\begin{array}{l}\text { HR Learning and } \\
\text { Development Manager }\end{array}$ & $\begin{array}{l}\text { Software } \\
\text { Development }\end{array}$ & End-user & 27.5 (total revenие) & \\
\hline $\mathrm{I} 10$ & $\begin{array}{l}\text { Business Intelligence } \\
\text { Consultant }\end{array}$ & Telecommunications & $\begin{array}{l}\text { End-user \& } \\
\text { Developer }\end{array}$ & 11.62 (net sales) & Swiss company \\
\hline I11 & Head of Data \& Analytics & $\begin{array}{l}\text { Management } \\
\text { Consulting }\end{array}$ & $\begin{array}{l}\text { End-user \& } \\
\text { Developer }\end{array}$ & 26.4 (revenue) & \multirow{3}{*}{$\begin{array}{l}\text { Multinational group } \\
\text { with a national } \\
\text { subsidiary in } \\
\text { Switzerland }\end{array}$} \\
\hline $\mathrm{I} 12$ & $\begin{array}{l}\text { Partner, Advisory \& } \\
\text { Forensic }\end{array}$ & $\begin{array}{l}\text { Management } \\
\text { Consulting }\end{array}$ & $\begin{array}{l}\text { End-user \& } \\
\text { Developer }\end{array}$ & 26.4 (геvепие) & \\
\hline $\mathrm{I} 13$ & HR Analyst & $\begin{array}{l}\text { Management } \\
\text { Consulting }\end{array}$ & $\begin{array}{l}\text { End-user \& } \\
\text { Developer }\end{array}$ & 26.4 (revenuе) & \\
\hline I14 & Founder & $\begin{array}{l}\text { Management } \\
\text { Consulting }\end{array}$ & Developer & 0 (start-up) & Swiss company \\
\hline I15 & Key Account Manager & Hardware/Software & Developer & 79.14 (revenue) & $\begin{array}{l}\text { Multinational group } \\
\text { with a national } \\
\text { subsidiary in Germany }\end{array}$ \\
\hline I16 & $\begin{array}{l}\text { Workforce \& Executive } \\
\text { Consulting Partner }\end{array}$ & Hardware/Software & Developer & 79.14 (revenue) & \multirow{2}{*}{$\begin{array}{l}\text { Multinational group } \\
\text { with a national } \\
\text { subsidiary in the UK }\end{array}$} \\
\hline $\mathrm{I} 17$ & $\begin{array}{l}\text { Global Director for People } \\
\text { Analytics Solutions }\end{array}$ & Hardware/Software & $\begin{array}{l}\text { End-user \& } \\
\text { Developer }\end{array}$ & 79.14 (revenue) & \\
\hline I18 & Founder \& CEO & $\begin{array}{l}\text { Management } \\
\text { Consulting }\end{array}$ & Developer & 0 (start-up) & German company \\
\hline I19 & $\begin{array}{l}\text { HR IS \& People } \\
\text { Analytics, HR Center of } \\
\text { Expertise Europe }\end{array}$ & $\begin{array}{l}\text { Energy \& } \\
\text { Automation }\end{array}$ & End-user & 34.3 (rеvепие) & Swiss company \\
\hline $\mathrm{I} 20$ & Data Protection Officer & Telecommunications & End-user & 1.08 (rеvепие) & \multirow{4}{*}{$\begin{array}{l}\text { Multinational group } \\
\text { with a national } \\
\text { subsidiary in } \\
\text { Switzerland }\end{array}$} \\
\hline $\mathrm{I} 21$ & $\begin{array}{l}\text { Talent Manager / Employee } \\
\text { Life Cycle }\end{array}$ & $\begin{array}{l}\text { Management } \\
\text { Consulting }\end{array}$ & Developer & 14.8 (revenue) & \\
\hline $\mathrm{I} 22$ & $\begin{array}{l}\text { Talent Manager / Employee } \\
\text { Life Cycle }\end{array}$ & $\begin{array}{l}\text { Management } \\
\text { Consulting }\end{array}$ & Developer & 14.8 (revenие) & \\
\hline $\mathrm{I} 23$ & $\begin{array}{l}\text { Analytics and Information } \\
\text { Manager }\end{array}$ & $\begin{array}{l}\text { Management } \\
\text { Consulting }\end{array}$ & Developer & 14.8 (revenue) & \\
\hline $\mathrm{I} 24$ & $\begin{array}{l}\text { HR Insight Leader / } \\
\text { Advanced People Analytics }\end{array}$ & $\begin{array}{l}\text { Banking and } \\
\text { Insurance }\end{array}$ & End-user & $\begin{array}{l}915.6 \text { (balance sheet } \\
\text { totals) }\end{array}$ & Swiss company \\
\hline $\mathrm{I} 25$ & $\begin{array}{l}\text { Product Consultant } \\
\text { Pre-sales }\end{array}$ & Hardware/Software & Developer & 0.038 (revenue) & \multirow{2}{*}{$\begin{array}{l}\text { Multinational group } \\
\text { with a national } \\
\text { subsidiary in } \\
\text { Switzerland }\end{array}$} \\
\hline $\mathrm{I} 26$ & $\begin{array}{l}\text { Product Consultant } \\
\text { Pre-sales }\end{array}$ & Hardware/Software & Developer & 0.038 (revenue) & \\
\hline
\end{tabular}


TABLE 2

\section{Exemplary Quotes From Semi-Structured Interviews (step 1)}

\begin{tabular}{|c|c|c|}
\hline DTCC Dimension & DTCC Element & Exemplary Quotes From the Interviews \\
\hline \multirow{2}{*}{$\begin{array}{l}\text { Type of Employment } \\
\text { Status }\end{array}$} & $\begin{array}{l}\text { Before-contract } \\
\text { DTCCs }\end{array}$ & $\begin{array}{l}\text { "We offer technologies that facilitate a smart search about a person - in particular, online - by indicating necessary information in a } \\
\text { specific way. Our partners, such as Company Alpha, deliver the technology for the automated matching of job candidate profiles with } \\
\text { job requirements in a highly targeted manner. In this way, we identify the most suitable candidates using semi-automated or fully- } \\
\text { automated tech solutions." }\end{array}$ \\
\hline & $\begin{array}{l}\text { After-contract } \\
\text { DTCCs }\end{array}$ & $\begin{array}{l}\text { "We are hesitant in Switzerland. We need only a little data, such as the social insurance identification number. The Swiss employee is } \\
\text { "alright" for us. In the U.S., we are more hesitant. As an employer, you are not allowed to know an employee's age, and there is also } \\
\text { no official retirement age. In Slovakia, the situation is different. At the start of the job, the employee needs to have an eye exam, as our } \\
\text { work requires a lot of computer-based tasks. The labor inspector checks the results regularly. We need to protect our employees' } \\
\text { health." }\end{array}$ \\
\hline \multirow{3}{*}{$\begin{array}{l}\text { DTCC Data Analysis } \\
\text { Purpose }\end{array}$} & Description & $\begin{array}{l}\text { "These are standard uses of tools, in my opinion. We aim at structuring all employee data in the company in a proper way, having } \\
\text { everything in one place and being able to start with analytics tools, to make sense of the data. Easy examples would be 'show me all } \\
\text { employees in the age range of } 50 \text { to } 60 \text { who earn more than } € 3.10 \text { and are based in Bonn.' That's easy. Every Excel tool is capable of } \\
\text { performing this task." }\end{array}$ \\
\hline & Prediction & $\begin{array}{l}\text { "Predictive analytics forecast future developments based on past patterns of behavior, and their use is increasing. Previously, most of } \\
\text { the data analysis has been used for retrospective analyses, either structured or unstructured. Now, it's much more about checking } \\
\text { whether someone is experienced, but might be off track. How do you get the person back on track to avoid this scenario happening in } \\
\text { the future? If you cannot correct the behavior, what would the future scenario look like, based on options indicated by algorithms?" }\end{array}$ \\
\hline & $\begin{array}{l}\text { Likelihood } \\
\text { Estimation }\end{array}$ & $\begin{array}{l}\text { "Did I get you right, that you can define, for instance, five variables, like summer holidays, airfares and some other things in my } \\
\text { regression model, and then use these data to estimate the absenteeism rate? ..." "Yeah, and then add some skills from the WATSON } \\
\text { technology, then you can estimate that the probability of absenteeism is } 30 \% \text { for that group of employees, based on the relationships } \\
\text { of the variables X, Y, Z from that regression model." }\end{array}$ \\
\hline DTCC Data Sources & Digital Sources & $\begin{array}{l}\text { "We collect data on how people collaborate. On one hand, we analyze e-mail communications and, on the other hand, we analyze } \\
\text { collaboration between people, based on who edits which files, sends them to whom, and how they are sent around in a company. We } \\
\text { call these 'document graphs.' We identify how people are connected through the use of files, how these files are edited and how people } \\
\text { communicate about them." }\end{array}$ \\
\hline
\end{tabular}


"In the past, one could only make a digital comparison of collaboration. Nowadays, you can combine that with a physical component, and that's where we are now - actually, on a very, very current project, which is exactly about this topic: integrating the physical Digital and Physical component and seeing where people sit and how people sit together, and how they collaborate, so to speak, in physical space and not Sources $\quad$ just digital space. And I think this is actually ... an example of an application where you say it is now with different sources, with different kinds of - uhm - data, and you mix them together and then look at them."

"On the HR side, technology offers several layers of analytics. On one hand, we do have access to personal data and development ...

Individual level what I can access besides the usual HR data is what we call the 'My Development Space' - an interactive cloud-based solution, including job vacancies, skills, competencies, profiles. This can be connected to a person's LinkedIn profile. You can design your profile, and act, based on the platform, to explore opportunities - longer-term, permanent or temporary."

Granularity of DTCC

Data Analysis and

Inferences

Team level

"We have defined key indicators, and you can relate yourself to a sort of benchmark that shows you how you perform in comparison to yourself over time, or in comparison to your team and with teams from other regions. You can never disclose information-indicating data that can be broken down to the individual employee level. My manager sees the score from his team. He can compare his team with the averages of other teams."

Organizational Level "These key indicators are clustered in a hierarchical manner, based on the region or country - Switzerland - and then within the region, by the specific area in which I am anchored within the group of 'Analytics.' The same logic applies up to the global level."

"The reports are configured in an easy manner. E-mails are not only analyzed with regard to HR, but also in connection with

On-the-job Datagathering compliance. For instance, the company has to intervene if an employee is drafting a bomb threat in an e-mail. The employer and the Swiss Intelligence Service then receive a notification. There are several compliance levels for self-protection. It requires a reaction against universal non-compliance, such as URL blocking measures."

Time Point of DTCC Data-gathering

Off-the-job Datagathering

"We have started collecting data with regard to health. An employee receives benefits when he/she is behaving in a more healthconscious manner. Health tracking is included in our campus agreement, and also applies to food. When you pre-order your food, it is tracked. The benefit is that you know exactly how many calories you are eating and burning, and how healthy you are. Company Alpha then also knows exactly what the people eat."

"In essence, it is about personal profiling that you can save. So, when you are working together as a team, and also in agile teams, you find out pretty quickly that an employee has got this and that profile. So, when I work with somebody with such a profile, I can take several points into consideration. You can feed the analytics system with additional aspects: work bundles that might come up, specific questions raised, or where you can add value to the discussion. How can your counterparts get to know you better? Another aspect would be to have regular check-ins, to give feedback with your manager. In this way, you should be able to demonstrate your strengths and identify where you added value. In terms of work climate, what did you enjoy doing? What did you not enjoy? It's about creating a visible profile of preferences and responding to individual weaknesses and strengths... It allows the construction of correlations concerning interactions, the use of strengths and so forth... The manager can construct personal profiles through a continuous database, and only the manager can access this data." 
"This would fall under the analytics area. But, as I said, I do not think the cyberspace model is as strong as what we are trying in a physical setting now. When you introduce the physical aspect into it, you know when people leave the office, when they are going away from their desks. I guess - and I am quite sure about it - it doesn't know whether I really look at something or whether I have opened a specific file or whether I just opened an e-mail. I am not quite sure what the system documents, but I know it is probably not very accurate. That's what I know..."

\begin{tabular}{|c|c|}
\hline Emerging Themes & Exemplary Quotes From the Interviews \\
\hline Normative Concerns & $\begin{array}{l}\text { - "We include ethical aspects if the client wishes us to do so. We would not monitor toilet breaks if that was against our clients wishes. } \\
\text { We aim at highlighting ethical concerns to our clients, where applicable; at the same time, the client decides the shape of the product. } \\
\text { There are conflicting ethical interests in companies. The workers' council requires transparency. At the same time, a recruiter can } \\
\text { record data that, potentially, no one else will ever know about." } \\
\text { "It's more of a regulatory question than a technical one, data protection, co-determination bodies, internal agreements and such } \\
\text { things. For example, Germany has very strict legal frameworks in this area, and we cannot analyze German employee data so easily } \\
\text { here in Switzerland, even though the data is located on servers here." } \\
\text { "The culture of the group determines the conduct in Switzerland. If a company is very data-driven in HR by group policy, it will try } \\
\text { to be as data-driven as possible in HR in Switzerland." }\end{array}$ \\
\hline Employee Perceptions & $\begin{array}{l}\text { - "So, from what I clearly see on the Swiss market,... unique identifying data is absolutely not in demand in Switzerland. The big } \\
\text { companies only do a very little bit - well, they simply know that the openness of the employees is not there yet. In America, we have } \\
\text { many more projects than here in Switzerland." } \\
\text { - "Data should make work easier for employees. Their work should improve, from a technical perspective. There are alternative data } \\
\text { sources outside of HR. For example, Company Alpha measures the use of workspaces through sensors beneath chairs. Company } \\
\text { Beta explicitly forgoes such HR protocols or evaluations of chair usage. You need to differentiate between the actual purpose of a } \\
\text { tech solution and the potential dangers for abuse of that very tech solution." } \\
\text { "If you built a machine in the 1900s, you would also clearly have to create awareness of the potentials and dangers around its usage } \\
\text { by the firm, and communicate this very clearly. Using tech tools requires a corresponding corporate culture, checks and balances, } \\
\text { and appreciation of a company's employees. The introduction of new tools needs to be accompanied by soft-skills training. It requires } \\
\text { trust on both sides." }\end{array}$ \\
\hline
\end{tabular}

Notes: The interview quotes have been translated from German into English. The company names have been anonymized by referring to them as Companies Alpha and Beta 


\section{TABLE 3}

\section{Overview of the Four Workshops with Scholarly Experts (step 2)}

\begin{tabular}{ll}
\hline \hline Workshop & Guiding Questions \\
\hline & General guiding question: \\
1 & $\begin{array}{l}\text { Are all relevant DTCC dimensions covered, } \\
\text { and are the categories clearly } \\
\text { distinguishable? }\end{array}$
\end{tabular}

Follow-up and deep-dive into emergent themes from expert interviews in step 1:

- How can the DTCC framework sufficiently account for issues relating to the normative background and institutional arrangements relating to DTCC execution in the workplace?

\section{Macro-level perspective}

(i.e., business ethics, macro-economics, strategic management, and employment/dataprotection law)

\section{Deepened Themes / \\ Gained Insights}

Normative safeguards

and institutional

arrangements need

further attention

\section{Impact on the Evolving Framework}

Revision of the framework based on the question of whether a dimension really is a systemic property or a contextual factor relating to the workplace (climate, culture, etc.)

- Relabeling of dimensions according to the system's property perspective (e.g., employees' knowledge on DTCCs' functionality $\rightarrow$ transparency. How precisely does the DTCC system inform employees of what is controlled and what is not?)

- A right to opt out of the DTCC appears to be a relevant system property from a business ethical and legal stance

- Data visibility appears to account for institutional safeguards relating to stakeholder involvement and privacy issues

\section{General guiding question:}

- Are all relevant DTCC dimensions covered, and are the categories clearly distinguishable?

Follow-up and deep-dive into emergent

themes from expert interviews in step 1:

- How can the DTCC framework sufficiently account for issues relating to employee perceptions towards DTCCs in the workplace?

\section{Meso-/micro-level}

perspective

(i.e., any type of organizational control,

and employee

perceptions such as

trust, motivation and

acceptance)
Employee perceptions appear relevant for an effective DTCC design
- Insights from HR practice research appears highly relevant for the dimension specification of "Data Visibility" and "Reference Group" into more categories per dimension

- Relabeling of "Digital vs. Digital and Physical Sources" as "Structured Data Sources vs. Unstructured Data Sources"

- Insights from enabling vs. coercive bureaucracies add to dimension precision and validity (e.g., opt-out as a safeguard for selfdetermination and autonomy, and data visibility as a token for employee integrity) 


\section{General guiding questions:}

- What is the marginal utility of each of the DTCC dimensions?

3 - Do dimensions and categories contradict each other; e.g., (cross-)consistency assessment?

\section{Framework-building} research methods

(i.e., typologies,

taxonomies,

morphological analysis methods)
Matching quality criteria of empirical taxonomies (Gregor, 2006; Meyer, 2007) with those of morphological analysis methods (Ritchey, 2012; Frow et al., 2015
- Streamline dimensions and categories because some DTCC properties are reflected only by the combination of others

- Streamline dimensions and categories because some DTCC properties are reflected by the number of morphotypes, representing one DTCC system (e.g., the volume of data)

- Data triangulation and a constant back and forth between empirical insights, literature and validation with other practitioners seem highly practical for meeting relevant quality criteria from both methods' strands

\section{General guiding questions:}

- Does the DTCC framework sufficiently account for organizational control theory?

- Do the dimensions and categories contradict each other from a theoretical stance?

\section{Follow-up and deep-dive into emergent} themes from expert interviews in step 1 and previous workshops:

- To what extent does our DTCC framework account for configurational control theory basic assumptions?

- Is there a need for a new conceptualization vs. enlargement of theory, and should relevant building blocks be reconsidered?

- How does technology impact organizational (control) systems?
Holistic perspective on control systems and knowledge of the effective balance of control practices

Configurational theory of al control technology as a and electronic challenge for the performance- functioning of monitoring organizations (design of control systems) and how control is executed (effective balancing and weighing of control practices)
- Relevance of employee participation in combination with the possibility to opt in vs. opt out (e.g., the non-occurrence of an opt-out option does not necessarily have the same impact on the psychological states of employees as the possibility to opt in)

- Empirical workplace phenomena challenge how various 'traditional' control elements can be efficiently and effectively balanced

- Specification of dimensions and elements (i.e., control targets also comprise norms and culture, and hence we discussed whether DTCC also formalizes informal control practices to a certain extent. What are the implications for configurational control theory?

- Revisit all dimensions against a background of formalizing informal controls. Does it still make sense? And what would an ideal DTCC configuration for conductive employee attitudes look like?

- Is the employee sense of autonomy sufficiently captured? Because technology alters the effective control practice balance and formalizes informal control efforts, and hence might restrict employees' sense of autonomy 
TABLE 4

Overview of Electronic Performance-Monitoring Design Options

\begin{tabular}{|c|c|}
\hline $\begin{array}{l}\text { Electronic Performance-Monitoring } \\
\text { Design Options }\end{array}$ & Exemplary References \\
\hline (1) Employee Participation & $\begin{array}{l}\text { - Electronic performance-monitoring literature directly addresses employee } \\
\text { participation, referring to it as employee control over monitoring, employee } \\
\text { voice, or employee contributions: e.g., Alder and Ambrose (2005); Alge } \\
\text { (2001); Ball and Margulis (2011); Chory, Vela, and Avtgis (2016); Jeske } \\
\text { (2011); Jeske and Kapasi (2017); Jeske and Santuzzi (2015); Kidwell and } \\
\text { Bennett (1994); McNall and Stanton (2011); Spitzmüller and Stanton (2006); } \\
\text { Stanton (2000a); Stanton and Barnes-Farrell (1996); Zweig and Scott (2007); } \\
\text { Zweig and Webster (2002) } \\
\text { - Electronic surveillance refers to employee participation via the "caring", } \\
\text { aspect of surveillance: e.g., Sewell and Barker (2006); Sewell, Barker, and } \\
\text { Nyberg (2012) } \\
\text { - Organizational control theory refers to employee participation via enabling } \\
\text { bureaucracy: e.g., Alder and Borys (1996) }\end{array}$ \\
\hline \multirow[t]{2}{*}{ (2) "Function Creep" } & $\begin{array}{l}\text { - Electronic performance monitoring refers to "function creep" as incomplete } \\
\text { employee awareness/knowledge of monitoring or inappropriate use of } \\
\text { monitoring: e.g., D'Urso (2006); Holton and Fuller (2008); Jeske (2011); } \\
\text { Rogers, Smith, and Sainfort (1990); Smith and Amick (1989); Stanton (2000a, } \\
\text { 2000b); Stanton and Barnes-Farrell (1996); Stanton and Weiss (2000) } \\
\text { - Electronic surveillance directly addresses "function creep" or refers to it as } \\
\text { incompletely informed consent: e.g., Ball (2010); Sutrop and Laas-Mikko } \\
\text { (2012); Tabak and Smith (2005) }\end{array}$ \\
\hline & $\begin{array}{l}\text { - Electronic performance monitoring refers to volume of data as } \\
\text { pervasiveness, amount of monitoring or frequency of monitoring: e.g., Alder } \\
\text { and Ambrose (2005); e.g., Bain and Taylor }(2000) \text {; Chang, Liu, and Lin } \\
\text { (2015); Grant and Higgins }(1989,1991)\end{array}$ \\
\hline \multirow[t]{2}{*}{ (3) Volume of Data } & $\begin{array}{l}\text { - Electronic surveillance refers to volume of data via the "coercive" aspect of } \\
\text { surveillance or as overcontrol: e.g., Grant and Higgins (1989); Sewell and } \\
\text { Barker (2006); Sewell et al. (2012); Vuokko (2008) }\end{array}$ \\
\hline & $\begin{array}{l}\text { - Organizational control theory refers to employee participation as coercive } \\
\text { bureaucracy: e.g., Alder and Borys (1996) }\end{array}$ \\
\hline
\end{tabular}


TABLE 5

Overview of the Evaluating and Validating Workshops with HR Practitioners (step 3)

\section{Practical application in $\mathbf{2 0}$ use cases from companies via discursive morphotyping (i.e., drawing lines to connect one control element per control dimension)}

\footnotetext{
We engaged in discursive prototyping exercises through the two use cases mentioned in this article: (1) ORION at UPS; and (2) Starmind at Company Alpha. Whenever possible, we additionally referred to practice examples from the HR departments of workshop participants' companies.

Exemplary questions from our discursive prototyping exercises:

- While connecting the boxes from top to bottom, could you kindly verbalize your thoughts; i.e., could you tell us why exactly you are connecting these boxes?

- Does our framework capture your company reality exhaustively?

- In your opinion, is there a dimension missing that you would say is important for best describing your company reality?

- Are there dimensions that you would say are not necessary for capturing your business reality?

- Do the dimensions and categories "make sense" from an application perspective?

○ Can you please summarize the configuration you have just drawn, in your own words?

o What do the other workshop participants think about this verbalization?

○ Does it convince you?

- Do logical and/or empirical (i.e., practical) inconsistencies remain?

○ How would you approach these inconsistencies?

- What do the others think about this solution to remove this flaw?
} 
FIGURE 1

\section{Development Steps Towards a DTCC Framework}

\begin{tabular}{|c|c|c|}
\hline \multicolumn{3}{|c|}{$\begin{array}{l}\text { Participant Selection \& Literature Review } \\
\text { - Constant monitoring of literature on configurational control theory and electronic performance monitoring } \\
\text { - What companies have to be approached in order to explore relevant DTCC dimensions and elements? } \\
\text { - What company experts are knowledgeable on technological properties and design options of DTCCs? } \\
\text { - Involvement of scholarly experts on configurational organizational control theory } \\
\text { - Involvement of HR practitioners }\end{array}$} \\
\hline \begin{tabular}{|c|} 
Step 1: \\
Identifying Control Design Options \\
of Datafication Technologies with \\
Experts
\end{tabular} & $\begin{array}{c}\text { Step 2: } \\
\text { Generating the Framework } \\
\text { on Datafication Technology } \\
\text { Control Configurations }\end{array}$ & $\begin{array}{c}\text { Step 3: } \\
\text { Evaluating and Validating } \\
\text { the DTCC Framework }\end{array}$ \\
\hline \multicolumn{3}{|c|}{ Aim: } \\
\hline $\begin{array}{l}\text { Exploring and gathering data on } \\
\text { datafication technology control } \\
\text { dimensions and elements }\end{array}$ & $\begin{array}{l}\text { Prototyping a DTCC framework that } \\
\text { meets the scientific criteria of } \\
\text { consistency, validity and parsimony }\end{array}$ & $\begin{array}{c}\text { Evaluating the DTCC framework on } \\
\text { the basis of plausibility and } \\
\text { relevance }\end{array}$ \\
\hline \multicolumn{3}{|c|}{ Guiding Questions: } \\
\hline $\begin{array}{c}\text { - What are people management and } \\
\text { organizational control in the eyes of } \\
\text { interviewed experts? } \\
\text { - What are the technological } \\
\text { properties and design-options of } \\
\text { datafication technologies and } \\
\text { digitalized organizational controls in } \\
\text { their company portfolio? } \\
\text { • How do these datafication } \\
\text { technology control solutions differ } \\
\text { from each other and "what do they } \\
\text { do"? } \\
\text { - What was the experience with the } \\
\text { implementation of datafication } \\
\text { technology controls so far? }\end{array}$ & $\begin{array}{l}\text { - Are all relevant DTCC dimensions } \\
\text { covered and are the elements clearly } \\
\text { distinguishable? } \\
\text { - Do dimensions and categories } \\
\text { contradict each other? } \\
\text { - What is the marginal utility of each of } \\
\text { the DTCC dimensions and elements? } \\
\text { - Does the DTCC framework } \\
\text { sufficiently account for organizational } \\
\text { control theory? }\end{array}$ & $\begin{array}{l}\text { - Does the framework capture the } \\
\text { organizaitonal reality exhaustively? } \\
\text { - Do the dimensions and categories } \\
\text { "make sense" from an application } \\
\text { perspective? }\end{array}$ \\
\hline \multicolumn{3}{|c|}{ Form of Interaction: } \\
\hline $\begin{array}{c}\text { Twenty-six semi-structured } \\
\text { interviews with technological experts }\end{array}$ & $\begin{array}{c}\text { One workshop with expert scholars } \\
\text { from a macro-level perspective } \\
\text { (business ethics, macro-economics, } \\
\text { strategic management and } \\
\text { employment/data protection law) } \\
\text { One workshop with expert scholars } \\
\text { from a meso-/micro-level perspective } \\
\text { (any type of organizational control and } \\
\text { employee perceptions, such as trust, } \\
\text { motivation and acceptance) } \\
\qquad \\
\text { One workshop with expert } \\
\text { scholars on taxonomies and } \\
\text { morphological analyses } \\
\mid \\
\text { One workshop with internationally } \\
\text { renowned scholars on configurational } \\
\text { control theory }\end{array}$ & $\begin{array}{l}\text { One workshop with HR practitioners } \\
\text { in the scope of executive teaching } \\
\text { classes } \\
\text { One in-company workshop with } \mathrm{HR} \\
\text { practitioners from a technology } \\
\text { forerunner company }\end{array}$ \\
\hline
\end{tabular}


FIGURE 3

Framework on Datafication Technology Control Configurations (DTCC)

\begin{tabular}{|c|c|c|c|c|c|c|c|}
\hline & \multicolumn{6}{|c|}{ DTCC - Elements } \\
\hline & & 1st Element & 2nd Element & 3rd Element & 4th Element & 5th Element & 6th Element \\
\hline \multirow{11}{*}{ 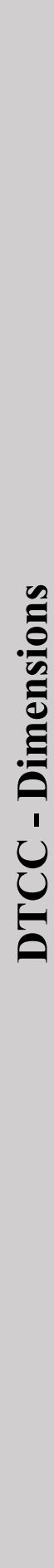 } & $\begin{array}{r}\text { (1) Control Timing } \\
\text { (When do DTCC systems execute employee control?) }\end{array}$ & Before Contracting & After Contracting & & & & \\
\hline & $\begin{array}{r}\text { (2) Target of Control } \\
\text { (What is the content of DTCC control activity?) }\end{array}$ & $\begin{array}{l}\text { Inputs/ } \\
\text { Personality }\end{array}$ & $\begin{array}{l}\text { Processes/ } \\
\text { Behaviors }\end{array}$ & $\begin{array}{l}\text { Performance/ } \\
\text { Outputs }\end{array}$ & $\begin{array}{l}\text { Norms/ } \\
\text { Culture }\end{array}$ & & \\
\hline & $\begin{array}{r}\text { (3) Control Scope } \\
\text { (Where does the DTCC system generate employee-related } \\
\text { information?) }\end{array}$ & $\begin{array}{l}\text { Task Performance } \\
\text { (on the premise) }\end{array}$ & $\begin{array}{l}\text { Contextual } \\
\text { Performance } \\
\text { (on the premise) }\end{array}$ & $\begin{array}{l}\text { Non-Job-Related } \\
\text { Behavior } \\
\text { (off the premise) }\end{array}$ & & & \\
\hline & $\begin{array}{r}\text { (4) Data Sources } \\
\text { (What data sources are available for DTCC execution?) }\end{array}$ & $\begin{array}{l}\text { Structured Data } \\
\text { Sources }\end{array}$ & $\begin{array}{l}\text { Unstructured Data } \\
\text { Sources }\end{array}$ & & & & \\
\hline & $\begin{array}{l}\text { (5) Openness for Employee Participation } \\
\text { (To what degree does the DTCC system allow employees to } \\
\text { contribute additional information on a voluntary basis?) }\end{array}$ & High & Low & & & & \\
\hline & $\begin{array}{r}\text { (6) Possibility for Employees to Opt Out } \\
\text { (Does the DTCC systems allow employees to evade DTCC control } \\
\text { or are they able to "turn the system off"?) }\end{array}$ & $\begin{array}{l}\text { Opt-in Options } \\
\text { possible }\end{array}$ & $\begin{array}{l}\text { Opt-out Options } \\
\text { possible }\end{array}$ & $\begin{array}{l}\text { No Opt-out Options } \\
\text { possible }\end{array}$ & & & \\
\hline & $\begin{array}{r}\text { (7) Transparency } \\
\text { (How precisely does the DTCC system inform employees of what is } \\
\text { controlled and what is not controlled?) }\end{array}$ & Full Disclosure & "Function Creep" & No Disclosure & & & \\
\hline & $\begin{array}{r}\text { (8) Granularity to which Inference is Possible } \\
\text { (To which organizational entity is the DTCC system able to draw } \\
\text { inference?) }\end{array}$ & Employee level & Team-/Division Level & Company Level & & & \\
\hline & $\begin{array}{r}\text { (9) Analytical Capacity } \\
\text { (To what extent does the DTCC system determine a management } \\
\text { decision?) }\end{array}$ & $\begin{array}{l}\text { Descriptive Analytics } \\
\text { (only status-quo description) }\end{array}$ & $\begin{array}{c}\text { Predictive Analytics } \\
\text { (outcome prediction possible, given } \\
\text { certain parameters) }\end{array}$ & $\begin{array}{l}\text { Prescriptive Analytics, } \\
\text { Artificial Intelligence } \\
\text { (likelihood of outcome occurrence } \\
\text { possible, given certain parameters) }\end{array}$ & & & \\
\hline & $\begin{array}{r}\text { (10) Reference Group } \\
\text { (To what reference point(s) is collected data compared to and } \\
\text { inference based on?) }\end{array}$ & $\begin{array}{l}\text { With oneself over } \\
\text { time }\end{array}$ & $\begin{array}{c}\text { With Peers inside the } \\
\text { Team }\end{array}$ & $\begin{array}{l}\text { With Peers in other } \\
\text { Teams }\end{array}$ & $\begin{array}{l}\text { With all Employees in } \\
\text { the Organization }\end{array}$ & $\begin{array}{l}\text { With Organizational \& } \\
\text { Industry Benchmarks / } \\
\text { Standards }\end{array}$ & \\
\hline & $\begin{array}{r}\text { (11) Data Visibility } \\
\text { (Who can access and evaluate the data emerging from DTCC } \\
\text { systems?) }\end{array}$ & Analyzed Employee & Line Manager & HR Department & Expert Committees & $\begin{array}{c}\text { Open Data Company } \\
\text { Access }\end{array}$ & $\begin{array}{l}\text { Open Third-Party } \\
\text { Access }\end{array}$ \\
\hline
\end{tabular}


FIGURE 4

\section{Depicting DTCCs - Two Exemplary Use Cases}

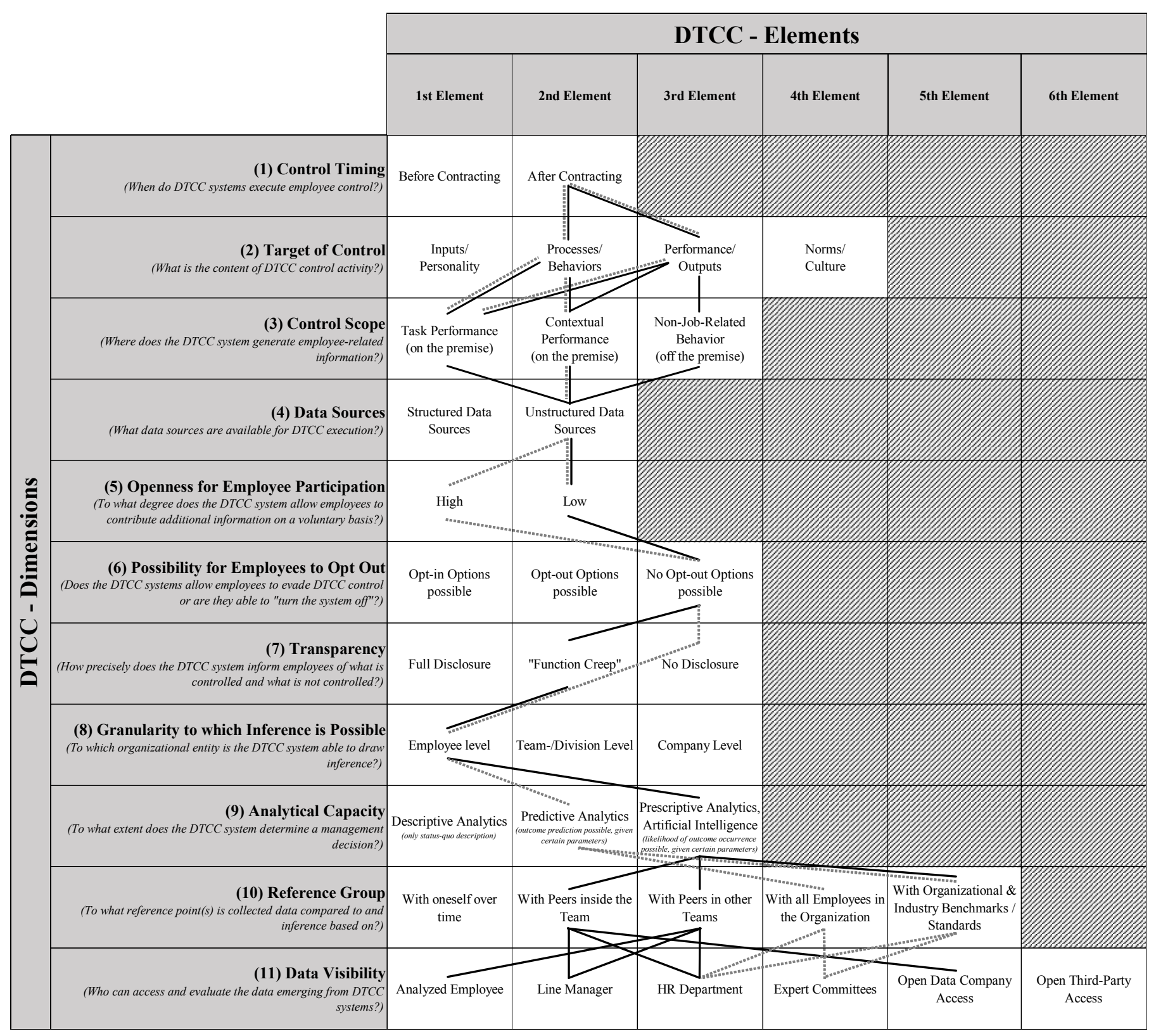




\section{REFERENCES}

REGULATION (EU) 2016/679. REGULATION (EU) 2016/679 OF THE EUROPEAN PARLIAMENT AND OF THE COUNCIL of 27 April 2016 on the protection of natural persons with regard to the processing of personal data and on the free movement of such data, and repealing Directive 95/46/EC (General Data Protection Regulation), L119: 1-88. European Union

Adler, P. S., \& Borys, B. 1996. Two types of bureaucracy: Enabling and coercive. Administrative Science Quarterly, 41(1): 61-89.

Aiello, J. R., \& Kolb, K. J. 1995. Electronic performance monitoring and social context: Impact on productivity and stress. Journal of Applied Psychology, 80(3): 339-353.

Alder, G. S. 2001. Employee reactions to electronic performance monitoring: A consequence of organizational culture. The Journal of High Technology Management Research, 12(2): 323-342.

Alder, G. S., \& Ambrose, M. L. 2005. An examination of the effect of computerized performance monitoring feedback on monitoring fairness, performance, and satisfaction. Organizational Behavior and Human Decision Processes, 97(2): 161-177.

Alder, P. S., \& Borys, B. 1996. Two types of bureaucracy: Enabling and coercive. Administrative Science Quarterly, 41(1): 61-89.

Alge, B. J. 2001. Effects of computer surveillance on perceptions of privacy and procedural justice. Journal of Applied Psychology, 86(4): 797-804.

Angrave, D., Charlwood, A., Kirkpatrick, I., Lawrence, M., \& Stuart, M. 2016. HR and analytics: Why HR is set to fail the big data challenge. Human Resource Management Journal, 26(1): 1-11.

Arciszewski, T. 2018. Morphological analysis in inventive engineering. Technological Forecasting and Social Change, 126: 92-101.

Ariely, D. 2017. Shapa: Small steps to a healthier you. Retrieved from: https:/www.myshapa.com/ (last access: April 14th, 2020)

Bacharach, S. B. 1989. Organizational theories: Some criteria for evaluation. Academy of Management Review, 14(4): 496-515.

Bain, P., \& Taylor, P. 2000. Entrapped by the 'electronic panopticon'? Worker resistance in the call centre. New Technology, Work and Employment, 15(1): 2-18.

Ball, K. 2010. Workplace surveillance: An overview. Labor History, 51(1): 87-106.

Ball, K., \& Margulis, S. T. 2011. Electronic monitoring and surveillance in call centres: A framework for investigation. New Technology, Work and Employment, 26(2): 113-126.

Bamberger, P. A. 2018. AMD - Clarifying what we are about and where we are going. Academy of Management Discoveries, 4(1): 1-10. 
Barker, J. R. 1993. Tightening the iron cage: Concertive control in self-managing teams. In C. Grey, \& H. Willmott (Eds.), Critical Management Studies. A Reader: 209-243. Oxford, UK: Oxford University Press.

Bassi, L. 2011. Raging debates in HR analytics. People and Strategy, 34(2): 14-18.

Bedford, D. S., \& Malmi, T. 2015. Configurations of control: An exploratory analysis. Management Accounting Research, 27: 2-26.

Bernstein, E. S. 2017. Making transparency transparent: The evolution of observation in management theory. Academy of Management Annals, 11(1): 217-266.

Bhave, D. P., Teo, L. H., \& Dalal, R. S. 2020. Privacy at work: A review and a research agenda for a contested terrain. Journal of Management, 46(1): 127-164.

boyd, d., \& Crawford, K. 2012. Critical questions for big data: Provocations for a cultural, technological, and scholarly phenomenon. Information, Communication \& Society, 15(5): 662-679.

Bruder, J. 2015. These workers have a new demand: Stop watching us, The Nation. Retrieved from: https://www.thenation.com/article/these-workers-have-new-demand-stop-watching-us/ (last access: April 14th, 2020).

Cardinal, L. B. 2001. Technological innovation in the pharmaceutical industry: The use of organizational control in managing research and development. Organization Science, 12(1): 19-36.

Cardinal, L. B., Kreutzer, M., \& Miller, C. 2017. An aspirational view of organizational control research: Re-invigorating empirical work to better meet the challenges of 21 st century organizations. Academy of Management Annals, 11(2): 559-592.

Cardinal, L. B., Sitkin, S. B., \& Long, C. P. 2004. Balancing and rebalancing in the creation and evolution of organizational control. Organization Science, 15(4): 411-431.

Cardinal, L. B., Sitkin, S. B., \& Long, C. P. 2010. A configurational theory of control. In S. B. Sitkin, L. B. Cardinal, \& K. Bijlsma-Frankema (Eds.), Organizational Control: 51-79. Cambridge, UK: Cambridge University Press.

Cardinal, L. B., Sitkin, S. B., Long, C. P., \& Miller, C. C. 2018. The genesis of control configurations during organizational founding. In B. Sitkin Sim (Ed.), Organization Design (Advances in Strategic Management), Vol. 40: 83-114: Emerald Publishing Limited.

Cascio, W. F., \& Montealegre, R. 2016. How technology is changing work and organizations. Annual Review of Organizational Psychology and Organizational Behavior, 3: 349-375.

Chamorro-Premuzic, T. 2016. Why a robot could be the best boss you've ever had, The Guardian. Retrieved from: https://www.theguardian.com/media-network/2016/sep/09/robot-boss-bestmanager-artificial-intelligence (last access: April 14th, 2020).

Chang, S. E., Liu, A. Y., \& Lin, S. 2015. Exploring privacy and trust for employee monitoring. Industrial Management \& Data Systems, 115(1): 88-106. 
Chory, R., Vela, L., \& Avtgis, T. 2016. Organizational surveillance of computer-mediated workplace communication: Employee privacy concerns and responses. Employee Responsibilities \& Rights Journal, 28(1): 23-43.

Choudhury, P., Allen, R., \& Endres, M. 2018. Developing theory using machine learning methods. Harvard Business School Working Paper 19-032 Available at SSRN 3251077: 1-48.

Costa, A. C., \& Bijlsma-Frankema, K. 2007. Trust and control interrelatedness: New perspectives on the trust-control nexus in organizational relations. Group \& Organization Management, 32 (4): 392406.

Crawford, K., \& Schultz, J. 2014. Big data and due process: Towards a framework to redress predictive privacy harms. Boston College Law Review 55(1): 93-128.

Cukier, K., \& Mayer-Schoenberger, V. 2013. The rise of big data. Foreign Affairs, 92(3): 27-40.

D'Urso, S. C. 2006. Who's watching us at work? Toward a structural-perceptual model of electronic monitoring and surveillance in organizations. Communication Theory, 16(3): 281-303.

Davenport, T. H. 2013. Analytics 3.0. Harvard Business Review, 91(12): 64-72.

DeBrusk, C. 2018. The risk of machine-learning bias (and how to prevent it), MIT Sloan Management Review. Retrieved from: https://sloanreview.mit.edu/article/the-risk-of-machine-learning-biasand-how-to-prevent-it/ (last access: April 14th, 2020).

DeHart-Davis, L. 2008. Green tape: A theory of effective organizational rules. Journal of Public Administration Research and Theory, 19(2): 361-384.

Dess, G. G., Newport, S., \& Rasheed, A. M. 1993. Configuration research in strategic management: Key issues and suggestions. Journal of Management, 19(4): 775-795.

DeTienne, K. B. 1993. Big brother or friendly coach? Computer monitoring in the 21 st century. The Futurist, 27(5): 33-37.

Dougherty, D. 2016. Taking advantage of emergence: Productively innovating in complex innovation systems. Oxford: Oxford University Press.

Eisenhardt, K. M. 1985. Control: Organizational and economic approaches. Management Science, 31(2): 134-149.

Eisenhardt, K. M. 1989. Building theories from case study research. Academy of Management Review, 14(4): 532-550.

Eisenhardt, K. M., \& Graebner, M. E. 2007. Theory building from cases: Opportunities and challenges. Academy of Management Journal, 50(1): 25-32.

Fayol, H. 1949. General and industrial administration. New York: Pitman.

Finlay, S. 2014. Predictive analytics, data mining and big data. Myths, misconceptions and methods. Hampshire (UK): Palgrave Macmillan UK. 
Flamholtz, E. G., Das, T. K., \& Tsui, A. S. 1985. Toward an integrative framework of organizational control. Accounting, Organizations and Society, 10(1): 35-50.

Fleming, D. E., \& Artis, A. B. 2010. Measuring corporate affinity for technology: A scale for customers and employees. Journal of Personal Selling \& Sales Management, 30(2): 167-179.

Frow, P., Nenonen, S., Payne, A., \& Storbacka, K. 2015. Managing co-creation design: A strategic approach to innovation. British Journal of Management, 26(3): 463-483.

Gasser, U., \& Almeida, V. A. 2017. A layered model for AI governance. IEEE Internet Computing(6): 58-62.

Gläser, J., \& Laudel, G. 2009. Experteninterviews und qualitative Inhaltsanalyse: Springer-Verlag.

Grant, R., \& Higgins, C. A. 1989. Monitoring service workers via computer: The effect on employees, productivity, and service. National Productivity Review, 8(2): 101-112.

Grant, R., \& Higgins, C. A. 1991. Computerized performance monitors: Factors affecting acceptance. IEEE Transactions on Engineering Management, 38(4): 306-315.

Hendrickx, F. 2018. Privacy, data protection and measuring employee performance. The triggers of technology and smart work. European Labour Law Journal, 9(2): 99-100.

Hitachi. 2015. Development of artificial antelligence issuing work orders based on understanding of onsite kaizen activity and demand fluctuation. Retrieved from: http://www.hitachi.com/New/cnews/month/2015/09/150904.pdf (last access: April 14th, 2020).

Holland, C., Levis, J., Nuggehalli, R., Santilli, B., \& Winters, J. 2017. UPS optimizes delivery routes. INFORMS Journal on Applied Analytics, 47(1): 8-23.

Holton, C. F., \& Fuller, R. M. 2008. Unintended consequences of electronic monitoring of instant messaging. IEEE Transactions on Professional Communication, 51(4): 381-395.

Hongo, J. 2015. Who's the boss? Hitachi looks to promote artificial intelligence, The Wall Street Journal. Retrieved from: http://blogs.wsj.com/japanrealtime/2015/09/08/whos-the-boss-hitachi-looks-topromote-artificial-intelligence/ (last access: April 14th, 2020).

Im, K., \& Cho, H. 2013. A systematic approach for developing a new business model using morphological analysis and integrated fuzzy approach. Expert Systems with Applications, 40(11): 4463-4477.

Jaworski, B. J. 1988. Toward a theory of marketing control: Environmental context, control types, and consequences. Journal of Marketing, 52(3): 23-39.

Jeske, D. 2011. Electronic performance monitoring: Employee perceptions and reactions. Northern Illinois University.

Jeske, D., \& Kapasi, I. 2017. Electronic Performance Monitoring: Lessons from the Past and Future Challenges, Annual Conference of the Italian Chapter of the Association of Information Systems. Milan, Italy. 
Jeske, D., \& Santuzzi, A. M. 2015. Monitoring what and how: Psychological implications of electronic performance monitoring. New Technology, Work and Employment, 30(1): 62-78.

Kepes, S., \& Delery, J. 2007. HRM systems and the problem of internal fit. In P. F. Boxall, J. Purcell, \& P. M. Wright (Eds.), The Oxford handbook of human resource management. Oxford: Oxford University Press.

Kidwell, R. E., \& Bennett, N. 1994. Employee reactions to electronic control systems: The role of procedural fairness. Group \& Organization Management, 19(2): 203-218.

Kirsch, L. J., Ko, D.-G., \& Haney, M. H. 2010. Investigating the antecedents of team-based clan control: Adding social capital as a predictor. Organization Science, 21(2): 469-489.

Konrad, A. 2013. Meet ORION, software that will save UPS millions by improving drivers' routes, Forbes. Retrieved from: https:/www.forbes.com/sites/alexkonrad/2013/11/01/meet-orion-software-thatwill-save-ups-millions-by-improving-drivers-routes/\#3f371804fc71 (last access: April 14th, 2020).

Krumeich, J., Werth, D., \& Loos, P. 2016. Prescriptive control of business processes - New potentials through predictive analytics of big data in the process manufacturing industry. Business $\boldsymbol{\&}$ Information Systems Engineering, 58(4): 261-280.

Kuckartz, U., \& Rädiker, S. 2019. Datenaufbereitung und Datenbereinigung in der qualitativen Sozialforschung. In N. Baur, \& J. Blasius (Eds.), Handbuch Methoden der empirischen Sozialforschung: 441-456. Wiesbaden: Springer Fachmedien Wiesbaden.

Kurasaki, K. S. 2000. Intercoder reliability for validating conclusions drawn from open-ended interview data. Field Methods, 12(3): 179-194.

Leicht-Deobald, U., Busch, T., Schank, C., Weibel, A., Schafheitle, S., Wildhaber, I., \& Kasper, G. 2019. The Challenges of Algorithm-Based HR Decision-Making for Personal Integrity. Journal of Business Ethics, 160(2): 377-392.

Linstone, H., \& Turoff, M. 2002. The delphi method: Techniques and applications Newark: New Jersey Institute of Technology.

Long, C. P., \& Sitkin, S. B. 2018. Control-trust dynamics in organizations: Identifying shared perspectives and charting conceptual fault lines. Academy of Management Annals, 12(2): 725-751.

Lycett, M. 2013. 'Datafication': Making sense of (big) data in a complex world. European Journal of Information Systems, 22(4): 381-386.

Mayring, P. 2015. Qualitative Inhaltsanalyse: Grundlagen und Techniken. Weinheim: Beltz.

McNall, L. A., \& Roch, S. G. 2009. A social exchange model of employee reactions to electronic performance monitoring. Human Performance, 22(3): 204-224.

McNall, L. A., \& Stanton, J. M. 2011. Private eyes are watching you: Reactions to location sensing technologies. Journal of Business and Psychology, 26(3): 299-309. 
Meckel, M. 2018. Mein Kopf gehört mir: Eine Reise durch die schöne neue Welt des Brainhacking. München: Piper

Ménard, C. 2009. Oliver Williamson and the logic of hybrid organizations. In M. Morroni (Ed.), Corporate Governance, Organization and the Firm. Co-operation and Outsourcing in the Global Economy: 87-103. Cheltenham: Edward Elgar Publishing.

Meyer, A. D., Tsui, A. S., \& Hinings, C. R. 1993. Configurational approaches to organizational analysis. Academy of Management Journal, 36(6): 1175-1195.

Meyer, R. 2007. Mapping the mind of the strategist: A quantitative methodology for measuring the strategic beliefs of executives. Rotterdam: Erasmus Research Institute of Management.

Miller, D. 1987. The genesis of configuration. Academy of Management Review, 12(4): 686-701.

Misangyi, V. F., Greckhamer, T., Furnari, S., Fiss, P. C., Crilly, D., \& Aguilera, R. 2017. Embracing causal complexity: The emergence of a neo-configurational perspective. Journal of Management, 43(1): 255-282.

Neff, G., \& Nafus, D. 2016. Self-tracking. Camebridge: MIT Press.

Normann, R. 2001. Reframing business: When the map changes the landscape. Chichester: John Wiley \& Sons.

Ouchi, W. G. 1979. A conceptual framework for the design of organizational control mechanisms. Management Science, 25(9): 833-848.

Ouchi, W. G. 1980. Markets, bureaucracies, and clans. Administrative Science Quarterly, 25(1): 129-141.

Ouchi, W. G., \& Maguire, M. A. 1975. Organizational control: Two functions. Administrative Science Quarterly, 20(4): 559-569.

Pasquale, F. 2015. The black box society: The secret algorithms that control money and information. Camebridge, MA: Harvard University Press.

Petre, J. 2018. Big brother is watching loo: Fears over 'smart' lavatory that can test users for drugs, pregnancy and urine problems, Daily Mail on Sunday. Retrieved from: https://www.dailymail.co.uk/news/article-5905047/Fears-smart-lavatory-test-users-drugspregnancy-urine-problems.html (last access: April 14th, 2020).

Phan, P., Wright, M., \& Lee, S.-H. 2017. Of robots, artificial intelligence, and work. Academy of Management Perspectives, 31(4): 253-255.

Prass1, J. 2018. Humans as a service: The promise and perils of work in the gig economy: Oxford University Press.

Prassl, J. 2019. What if your boss was an algorithm? Economic incentives, legal challenges, and the rise of artificial intelligence at work. Comparative Labor Law and Policy Journal(Special Issue “Automation, Artificial Intelligence and Labour Protection”). 
Ragin, C. C. 2008. Redesigning social inquiry: Fuzzy sets and beyond. Chicago: University of Chicago Press.

Ritchey, T. 2002. General morphological analysis - A general method for non-quantified modelling. Swedish Morphological Society: 1-10.

Ritchey, T. 2011. Wicked problems-social messes: Decision support modelling with morphological analysis. Berlin: Springer Science \& Business Media.

Ritchey, T. 2012. Outline for a morphology of modelling methods: Contribution to a General Theory of Modelling. Acta Morphologica Generalis, 1(1): 1-20.

Roberts, J. 2010. Designing incentives in organizations. Journal of Institutional Economics, 6(1): 125132.

Rogers, K. J. S., Smith, M. J., \& Sainfort, P. C. 1990. Electronic performance monitoring, job design and psychological stress. Proceedings of the Human Factors Society Annual Meeting, 34(12): 854858.

Sandelin, M. 2008. Operation of management control practices as a package-A case study on control system variety in a growth firm context. Management Accounting Research, 19(4): 324-343.

Sandle, T. 2018. Q\&A: Applying neuroscientific principles to AI, Digital Journal. Retrieved from: http://www.digitaljournal.com/tech-and-science/technology/q-a-applying-neuroscientificprinciples-to-ai/article/526758 (last access: April 14th, 2020).

Sapegina, A., \& Weibel, A. 2017. The good, the not so bad, and the ugly of competitive human resource practices: A multidisciplinary conceptual framework. Group \& Organization Management, 42(5): 707-747.

Searle, R., den Hartog, D. N., Weibel, A., Gillespie, N., Six, F., Hatzakis, T., \& Skinner, D. 2011. Trust in the employer: The role of high-involvement work practices and procedural justice in European organizations. The International Journal of Human Resource Management, 22(5): 1069-1092.

Seidenstricker, S., Rauch, E., \& Dallasega, P. 2017. Industrie-4.0-Geschäftsmodell-Innovation für KMU. ZWF Zeitschrift für wirtschaftlichen Fabrikbetrieb, 112(9): 616-620.

Seidenstricker, S., Scheuerle, S., \& Linder, C. 2014. Business model prototyping - Using the morphological analysis to develop new business models. Procedia-Social and Behavioral Sciences, 148: 102109.

Sewell, G., \& Barker, J. R. 2006. Coercion versus care: Using irony to make sense of organizational surveillance. Academy of Management Review, 31(4): 934-961.

Sewell, G., Barker, J. R., \& Nyberg, D. 2012. Working under intensive surveillance: When does 'measuring everything that moves' become intolerable? Human Relations, 65(2): 189-215.

Short, J. C., Payne, G. T., \& Ketchen Jr, D. J. 2008. Research on organizational configurations: Past accomplishments and future challenges. Journal of Management, 34(6): 1053-1079. 
Simons, R. 1994. How new top managers use control systems as levers of strategic renewal. Strategic Management Journal, 15(3): 169-189.

Sitkin, S. B., Cardinal, L. B., \& Bijlsma-Frankema, K. M. 2010. Organizational Control. Camebridge (UK): Camebridge University Press.

Sitkin, S. B., Sutcliffe, K. M., \& Schroeder, R. G. 1994. Distinguishing control from learning in total quality management: A contingency perspective. Academy of Management Review, 19(3): 537-564.

Smith, M. J., \& Amick, B. C. 1989. Electronic monitoring at the workplace: Implications for employee control and job stress. Job control and worker health: 275-290.

Snell, S. A. 1992. Control theory in strategic human resource management: The mediating effect of administrative information. Academy of Management Journal, 35(2): 292-327.

Solon, O. 2017. Big brother isn't just watching: Workplace surveillance can track your every move, The Guardian. Retrieved from: https://www.theguardian.com/world/2017/nov/06/workplacesurveillance-big-brother-technology (last access: April 14th, 2020).

Spiggle, S. 1994. Analysis and interpretation of qualitative data in consumer research. Journal of Consumer Research, 21(3): 491-503.

Spitzmüller, C., \& Stanton, J. M. 2006. Examining employee compliance with organizational surveillance and monitoring. Journal of Occupational and Organizational Psychology, 79(2): 245-272.

Stanton, J. M. 2000a. Reactions to employee performance monitoring: Framework, review, and research directions. Human Performance, 13(1): 85-113.

Stanton, J. M. 2000b. Traditional and electronic monitoring from an organizational justice perspective. Journal of Business and Psychology, 15(1): 129-147.

Stanton, J. M., \& Barnes-Farrell, J. L. 1996. Effects of electronic performance monitoring on personal control, task satisfaction, and task performance. Journal of Applied Psychology, 81(6): 738-745.

Stanton, J. M., \& Weiss, E. M. 2000. Electronic monitoring in their own words: An exploratory study of employees' experiences with new types of surveillance. Computers in Human Behavior, 16(4): 423-440.

Starmind. 2019a. Starmind case studies: Achieve better business outcomes with starmind.

Starmind. 2019b. User score settings resources.

Stone, D. L., \& Kotch, D. A. 1989. Individuals' attitudes toward organizational drug testing policies and practices. Journal of Applied Psychology, 74(3): 518-521.

Strauss, E., Kristandl, G., \& Quinn, M. 2015. The effects of cloud technology on management accounting and decision-making. Management and Financial Accounting Report, 10(6): 1-12.

Sutrop, M., \& Laas-Mikko, K. 2012. From identity verification to behavior prediction: Ethical implications of second generation biometrics. Review of Policy Research, 29(1): 21-36. 
Tabak, F., \& Smith, W. P. 2005. Privacy and electronic monitoring in the workplace: A model of managerial cognition and relational trust development. Employee Responsibilities and Rights Journal, 17(3): 173-189.

Tannenbaum, A. S. 1962. Control in organizations: Individual adjustment and organizational performance. Administrative Science Quarterly, 7(2): 236-257.

Tomczak, D. L., Lanzo, L. A., \& Aguinis, H. 2018. Evidence-based recommendations for employee performance monitoring. Business Horizons, 61(2): 251-259.

Turley, R. E., Richardson, W. C., \& Hansen, J. V. 1975. Morphological analysis for health care systems planning. Socio-Economic Planning Sciences, 9(2): 83-88.

Vlaar, P. W., Van den Bosch, F. A., \& Volberda, H. W. 2007. On the evolution of trust, distrust, and formal coordination and control in interorganizational relationships: Toward an integrative framework. Group \& Organization Management, 32(4): 407-428.

von Krogh, G. 2018. Artificial intelligence in organizations: New opportunities for phenomenon-based theorizing. Academy of Management Discoveries, 4(4): 404-409.

Vuokko, R. 2008. Surveillance at workplace and at home: Social issues in transforming care work with mobile technology. Journal of Information, Communication and Ethics in Society, 6(1): 60-75.

Wang, A. X., \& MacLellan, L. 2018. Herman Miller's new aeron chair is an office spy, collecting data on your every move, Quartz Work.

Weber, M. 1922. Wirtschaft und Gesellschaft. Grundriss der verstehenden Soziologie. Tübingen: Mohr Siebeck Verlag.

Weber, R. H. 2013. Transborder data transfers: Concepts, regulatory approaches and new legislative initiatives. International Data Privacy Law, 3(2): 117-130.

Weibel, A. 2007. Formal Control and Trustworthiness: Shall the Twain Never Meet? Group \& Organization Management, 32(4): 500-517.

Weibel, A., \& Six, F. 2013. Trust and control: The role of intrinsic motivation. In R. Bachmann, \& A. Zaheer (Eds.), Handbook of Advances in Trust: 57-81. Northampton: Edward Elgar Publishing inc.

Wilding, R., Sharif, A. M., \& Irani, Z. 2006. Applying a fuzzy-morphological approach to complexity within management decision making. Management Decision, 44(7): 930-961.

Witzel, A., \& Reiter, H. 2012. The problem-centred interview: Principles and practice. London: SAGE Publications Ltd. .

Woyke, E. 2018. Slack Hopes Its AI Will Keep You from Hating Slack. In M. T. Review (Ed.), MIT Technology Review. Retrieved from: https://www.technologyreview.com/s/609319/slack-hopesits-ai-will-keep-you-from-hating-slack/ (last access: April 14th, 2020). 
Wright, G. 2015. Employee Feedback Apps on the Rise - Using Technology for Real-Time Employee Performance Reviews, SHRM - Society for Human Resource Management.

Yin, R. K. 2018. Case study research and applications: Design and methods. Los Angeles: Sage Publications.

Zax, D. 2013. Brown Down: UPS drivers vs. the UPS algorithm, FastCompany. Retrieved from: https://www.fastcompany.com/3004319/brown-down-ups-drivers-vs-ups-algorithm (last acces: April 14th, 2020).

Zott, C., \& Huy, Q. N. 2007. How entrepreneurs use symbolic management to acquire resources. Administrative Science Quarterly, 52(1): 70-105.

Zuboff, S. 2019. The age of surveillance capitalism: The fight for a human future at the new frontier of power. New York: Public Affairs.

Zweig, D., \& Scott, K. 2007. When unfairness matters most: Supervisory violations of electronic monitoring practices. Human Resource Management Journal, 17(3): 227-247.

Zweig, D., \& Webster, J. 2002. Where is the line between benign and invasive? An examination of psychological barriers to the acceptance of awareness monitoring systems. Journal of Organizational Behavior: The International Journal of Industrial, Occupational and Organizational Psychology and Behavior, 23(5): 605-633.

Zwicky, F. 1969. Discovery, invention, research through the morphological approach. Toronto: The Macmillan Company.

\section{BIOGRAPHICAL SKETCHES}

Simon Schafheitle (simondaniel.schafheitle@unisg.ch) is an SNSF Research Fellow at the Institute for Work and Employment Research at the University of St. Gallen (FAA-HSG), from which he received his 
Ph.D. in Management. His research interests include datafication technologies in the workplace, trust in and between organizations, quasi-experimental research methods, and principles of evidence-based management. Address: University of St Gallen, FAA-HSG, Müller-Friedberg Strasse 6/8, 9000 St. Gallen, Switzerland.

Antoinette Weibel (antoinette.weibel@unisg.ch) is Full Professor for HRM at the University of St. Gallen and Director of the Institute for Work and Employment Research (FAA-HSG). She received her Ph.D. in Management from the University of Zurich. Her research interests are centered on trust and distrust within and between organizations. She is the principal of the SNSF research group on datafication technologies and trust and also leads several projects on the impact of HR on trust and distrust. Address: University of St Gallen, FAA-HSG, Müller-Friedberg Strasse 6/8, 9000 St. Gallen, Switzerland.

Isabel Ebert (isabel.ebert@unisg.ch) is a Ph.D. candidate and Research Associate at the Institute of Business Ethics at the University of St. Gallen, and a visiting researcher at the Oxford Internet Institute, University of Oxford. She holds an M.A. in International Relations, Peace and Conflict Studies from Goethe University of Frankfurt. Her research interests include digital corporate responsibility, business and human rights in the data economy, as well as privacy and sustainability of digital business models. Address: University of St. Gallen, IWE-HSG, Girtannerstrasse 8, 9010 St. Gallen, Switzerland.

Gabriel Kasper (gabriel.kasper@unisg.ch) is an attorney-at-law and a Ph.D. candidate at the Institute for Work and Employment Research at the University of St. Gallen (FAA-HSG). He received his master's degree in law from the University of Zurich. His research centers around the data protection and employment law implications of people analytics. Address: University of St Gallen, FAA-HSG, MüllerFriedberg Strasse 6/8, 9000 St. Gallen, Switzerland. 
Christoph Schank (christoph.schank@uni-vechta.de) is an Assistant Professor for Business Ethics at the University of Vechta (Germany) and as Head of CSR Management and Education also associated at the Institute for Business Ethics, where he is responsible for executive education in the field of corporate social responsibility. He holds a Ph.D. in Economics and studied Business Administration, Sociology and Labor Studies in Germany and the UK. His research interests include business ethics, corporate responsibility, algorithm-based decision making, and socio-economics education. Address: University of Vechta, Driverstraße 22, 49377 Vechta, Germany.

Ulrich Leicht-Deobald (ulrich.leicht-deobald@unisg.ch) is a Senior Research Fellow at the Institute for Business Ethics at the University of St. Gallen and a Visiting Fellow at the University of Groningen. His research centers around New Ways of Working. He received his Ph.D. in Management from the University of St. Gallen. Address: University of St Gallen, IWE-HSG, Girtannerstrasse 8, 9010 St. Gallen, Switzerland. 